\title{
Management of Crohn's disease in Taiwan: consensus guideline of the Taiwan Society of Inflammatory Bowel Disease
}

\author{
Shu-Chen Wei ${ }^{1}$, Ting-An Chang ${ }^{2}$, Te-Hsin Chao ${ }^{3}$, Jinn-Shiun Chen ${ }^{4}$, Jen-Wei Chou ${ }^{5}$, Yenn-Hwei Chou ${ }^{6}$, \\ Chiao-Hsiung Chuang ${ }^{7}$, Wen-Hung Hsu ${ }^{8}$, Tien-Yu Huang ${ }^{9}$, Tzu-Chi Hsu ${ }^{10}$, Chun-Chi Lin ${ }^{11}$, \\ Hung-Hsin $\operatorname{Lin}^{11,12}$, Jen-Kou Lin ${ }^{11}$, Wei-Chen Lin ${ }^{13}$, Yen-Hsuan $\mathrm{Ni}^{14}$, Ming-Jium Shieh ${ }^{15}$, I-Lun Shih ${ }^{16}$, \\ Chia-Tung Shun ${ }^{17}$, Yuk-Ming Tsang ${ }^{18}$, Cheng-Yi Wang ${ }^{1}$, Horng-Yuan Wang ${ }^{19,20,21}$, Meng-Tzu Weng ${ }^{22}$, \\ Deng-Chyang $\mathrm{Wu}^{23,24}$, Wen-Chieh $\mathrm{Wu}^{25}$, Hsu-Heng Yen ${ }^{26}$, Jau-Min Wong ${ }^{1}$ \\ ${ }^{I}$ Department of Internal Medicine, National Taiwan University Hospital, National Taiwan University College of Medicine, Taipei, ${ }^{2}$ Department \\ of Pathology, Taipei City Hospital Renai Branch, Taipei, ${ }^{3}$ Division of Colorectal Surgery, Department of Surgery, Taichung Veterans General \\ Hospital, Taichung, ${ }^{4}$ Division of Colorectal Surgery, Chang Gung Memorial Hospital at Linkou, Taoyuan, ${ }^{5}$ Division of Gastroenterology and \\ Hepatology, Department of Internal Medicine, China Medical University Hospital, Taichung, ${ }^{6}$ Division of General Surgery, Department of \\ Surgery, Shin Kong Wu Ho-Su Memorial Hospital, Taipei, ${ }^{7}$ Department of Internal Medicine, National Cheng Kung University Hospital, \\ National Cheng Kung University College of Medicine, Tainan, ${ }^{8}$ Division of Gastroenterology, Department of Internal Medicine, Kaohsiung \\ Municipal Hsiaokang Hospital, Kaohsiung, ${ }^{9}$ Division of Gastroenterology, Department of Internal Medicine, Tri-Service General Hospital, \\ National Defense Medical Center, Taipei, ${ }^{10}$ Division of Colon and Rectal Surgery, Department of Surgery, Mackay Memorial Hospital, Taipei, \\ ${ }^{11}$ Division of Colon and Rectal Surgery, Department of Surgery, Taipei Veterans General Hospital, Taipei, ${ }^{12}$ Department of Surgery, National \\ Yang-Ming University, Taipei, ${ }^{13}$ Department of Internal Medicine, Mackay Memorial Hospital, Taipei, ${ }^{14}$ Department of Pediatrics, National \\ Taiwan University Hospital, Taipei, Departments of ${ }^{15}$ Oncology, ${ }^{16}$ Medical Imaging, and ${ }^{17}$ Pathology and Forensic Medicine, National Taiwan \\ University Hospital, National Taiwan University College of Medicine, Taipei, ${ }^{18}$ Division of Medical Imaging, Department of Radiology, Far \\ Eastern Memorial Hospital, New Taipei City, ${ }^{19}$ Division of Gastroenterology, Department of Internal Medicine, MacKay Memorial Hospital, \\ Taipei, ${ }^{20}$ MacKay Junior College of Medicine, Nursing, and Management, Taipei, ${ }^{21}$ MacKay Medical College, New Taipei City, ${ }^{22}$ Department \\ of Internal Medicine, Far Eastern Memorial Hospital, New Taipei City, ${ }^{23}$ Division of Gastroenterology, Department of Internal Medicine, \\ Kaohsiung Medical University Hospital, Kaohsiung Medical University, Kaohsiung, ${ }^{24}$ Department of Internal Medicine, Kaohsiung Municipal \\ Ta-Tung Hospital, Kaohsiung, ${ }^{25}$ Division of Gastroenterology, Department of Medicine, Taipei City Hospital Renai Branch, Taipei, ${ }^{26}$ Division of \\ Gastroenterology, Department of Internal Medicine, Changhua Christian Hospital, Changhua, Taiwan
}

Crohn's disease (CD) is a chronic relapsing and remitting inflammatory disease of the gastrointestinal tract. CD is rare in Taiwan and other Asian countries, but its prevalence and incidence have been steadily increasing. A steering committee was established by the Taiwan Society of Inflammatory Bowel Disease to formulate statements on the diagnosis and management of CD taking into account currently available evidence and the expert opinion of the committee. Thorough clinical, endoscopic, and histological assessments are required for accurate diagnosis of CD. Computed tomography and magnetic resonance imaging are complementary to endoscopic evaluation for disease staging and detecting complications. The goals of CD management are to induce and maintain remission, reduce the risk of complications, and improve quality of life. Corticosteroids are the mainstay for inducing re-mission. Immunomodulating and biologic therapies should be used to maintain remission. Patients should be evaluated for hepatitis B virus and tuberculosis infection prior to treatment and receive regular surveillance for cancer. These consensus statements are based on current local evidence with consideration of factors, and could be serve

Received March 13, 2017. Revised May 2, 2017. Accepted May 2, 2017.

Correspondence to Jau-Min Wong, Department of Internal Medicine, National Taiwan University Hospital, National Taiwan University College of Medicine, No.7 Chung-Shan South Road, Taipei 101, Taiwan. Tel: +886-2-23123156, Fax:+886-2-23940049, E-mail: jmwong@ntu.edu.tw

Financial support: None. Conflict of interest: None.

\footnotetext{
( ) Copyright 2017. Korean Association for the Study of Intestinal Diseases. All rights reserved.

This is an Open Access article distributed under the terms of the Creative Commons Attribution Non-Commercial License (http://creativecommons.org/licenses/by-nc/4.0)

which permits unrestricted non-commercial use, distribution, and reproduction in any medium, provided the original work is properly cited.
} 
as concise and practical guidelines for supporting clinicians in the management of patients with CD in Taiwan. (Intest Res 2017;15:285-310)

Key Words: Taiwan; Crohn disease; Inflammatory bowel diseases; Disease management; Consensus statements

\section{INTRODUCTION}

Crohn's disease (CD), a form of IBD, is an immune-mediated disorder characterized by alternating periods of active disease and remission that can affect all segments of the gastrointestinal tract. Typically, inflammation is segmental, asymmetrical, transmural, and located in the terminal ileum and colon. ${ }^{1}$ CD causes considerable morbidity, and mortality in CD was higher than expected in some populationbased studies, including one conducted in Taiwan. ${ }^{2-4}$ Goals of CD therapy include inducing and maintaining remission, reducing the risk of complications, and improving quality of life. The incidence and prevalence of $\mathrm{CD}$ have been steadily rising in Taiwan and other Asian countries, though rates are still lower than in Western countries. ${ }^{5-8}$ While CD is less common in Asia, the severity of CD phenotype appears to be similar between Asia and the West. ${ }^{9}$

Guidelines for the diagnosis and management of CD have been developed in Europe, North America, and Asia Pacific; ${ }^{10-15}$ however, these guidelines are not entirely applicable to clinical practice in Taiwan due to differences in endemic diseases, disease distribution and behavior, and insurance coverage of treatments. The National Health Insurance (NHI) is a mandatory social health insurance system established in 1995, which now covers over 99\% of Taiwan's population. ${ }^{16}$ IBD is classified as a catastrophic illness under NHI, allowing CD patients to receive treatments that are reimbursed by NHI without copayment. Owing to the differences in the medical environment between Taiwan and other countries, guidelines for the management of CD that are specific to Taiwan are warranted.

A steering committee was established by the Taiwan Society of Inflammatory Bowel Disease (TSIBD) with the goal of developing expert consensus statements for the diagnosis and management of CD that take into account recommendations from international guidelines as well as factors with specific relevance to Taiwan. These guidelines are recommendations only and are not to be used in place of clinical judgement. Practitioners must take into consideration individual patient factors as well as the facilities and treatments that are available in their respective institutions in the clini- cal decision-making process.

\section{METHODS}

An expert panel comprising 27 gastroenterologists, surgeons, radiologists, and pathologists was established by TSIBD. Statements detailing recommendations for the clinical management of CD were drafted by the steering committee after careful consideration of available evidence and existing guidelines, particularly those developed by the European Crohn's and Colitis Organization and the Asian Pacific Association of Gastroenterology. Open discussion of the evidence for and against each statement and of suggested modifications to the statements was conducted at faceto-face meetings of the entire expert panel. Panel members expressed their agreeance with each finalized statement as "strongly agree," "agree," or "disagree." Consensus was considered to be achieved when $90 \%$ or above of voting members indicated "strongly agree" or "agree." Degree of agreeance reflects the strength of recommendation of each statement.

\section{RESULTS}

\section{Epidemiology}

\section{Statement 1.1}

CD is uncommon in Taiwan, but incidence and prevalence are increasing.

- Level of agreement: strongly agree 75\%, agree 25\%, disagree 0\%

The incidence and prevalence of CD in Taiwan steadily rose from 2000 to 2010, as revealed in an analysis of data from the population-based Taiwan National Health Insurance Research Database (NHIRD). ${ }^{7}$ The incidence of CD was 0.318 (95\% CI, $0.216-0.421)$ per 100,000 males and 0.210 (95\% CI, $0.128-0.293$ ) per 100,000 females in 2010, considerably higher than the rates observed in 2000 , which were 0.195 (95\% CI, 0.113-0.276) per 100,000 males and 0.092 (95\% CI, 0.035-0.149) per 100,000 females in 2010. The prevalence per 100,000 males and females has accordingly increased from 0.441 (95\% CI, 0.328-0.580) and 0.216 
(95\% CI, 0.138-0.321), respectively, in 2000 to 1.949 (95\% CI, 1.705-2.219) and 0.883 (95\% CI, 0.723-1.067), respectively, in 2010. More recently, another National health insurance research database (NHIRD)-based epidemiological study found the prevalence of CD in Taiwan in 2013 to be 3.5 per 100,000 persons. $^{8}$

Incidence rate of $\mathrm{CD}$ varies by geographical region worldwide and is highest in Europe and North America. ${ }^{5}$ The CD incidence rates in North America and Europe have been reported to be up to 20.2 and 12.7 per 100,000 persons, respectively. ${ }^{6,17}$ Over the past few decades, the incidence of CD has rapidly increased in Asia, a region where IBD frequency was initially low. ${ }^{6,18}$ Recent estimates of CD incidence rates range between 0.07 and 3.20 per 100,000 persons in China, Japan, South Korea, Hong Kong and Singapore. ${ }^{5,9,18}$ The rising incidence of CD in Taiwan and other Asian countries could be attributed to an increasingly "Western" lifestyle, though increased disease awareness and diagnosis are also possible explanations. $^{19,20}$

\section{Statement 1.2}

Unlike in Western countries, CD patients are predominantly male in Taiwan.

- Level of agreement: strongly agree 50\%, agree 50\%, disagree 0\%

Of a total of 526 incident cases of CD recorded in NHIRD between 2000 and 2010, 69\% (n=363) were male. ${ }^{7}$ Male predominance (male, $61.4 \%$ ) was also observed in a population-based analysis of CD incidence in China, Hong Kong, Indonesia, Macau, Malaysia, Singapore, Sri Lanka, and Thailand. ${ }^{9}$ Furthermore, $67 \%$ and $70 \%$ of incident cases of CD were male in South Korea and Japan, respectively. ${ }^{21,22}$ In contrast, epidemiological studies conducted in countries with predominantly Caucasian populations have shown higher incidence of CD in females., ${ }^{9,23-25}$

\section{Statement 1.3 \\ The genetic background of CD in Taiwan seems to be different from that in Western countries. \\ - Level of agreement: strongly agree 50\%, agree 50\%, disagree 0\%}

In populations of European descent, mutations in CARD15 (also known as NOD2) are strongly associated with risk of CD. ${ }^{26,27}$ CARD15 mutations, however, are absent in Asian CD patients, including those in Taiwan. ${ }^{28-31}$ Genetic analysis of 110 CD patients treated at the National Taiwan University Hospital revealed that TNFSF15 and ATG16L1 were significantly associated with risk of CD. ${ }^{32}$ TNFSF15 has also been reported to be associated with CD in Japan, Korea, and
Europe. $^{33-35}$ ATG16L1 variants, which are associated with impaired bacterial handling and decreased antibacterial defense, have been reported to be associated with CD risk in Europe, New Zealand, Australia, and Canada. ${ }^{36-41}$ Interestingly, ATG16L1 was not shown to be associated with CDsusceptibility in studies conducted in Japan, Korea, and China. ${ }^{33,42,43}$ Association between genotypic characteristics and phenotypic presentation, disease course, and response to therapy in CD require further study.

\section{Diagnosis}

\section{Statement 2.1}

$C D$ is a chronic inflammatory disease of the gastrointestinal tract. A single gold standard for the diagnosis of $C D$ is not available. The diagnosis of $C D$ is based on a combination of clinical, endoscopic, radiological, and histological features and the exclusion of an infectious etiology.

- Level of agreement: strongly agree $75 \%$, agree $20 \%$, disagree $5 \%$

For the diagnosis of CD, medical history, clinical evaluation, and typical endoscopic and histological findings must all be taken into consideration as there is no single diagnostic marker. Of particular importance is the exclusion of infectious etiology, as the features of infectious colitis, including those of bacterial, viral, and amebic causes, mimic those of $\mathrm{CD}^{44,45}$ Presence of granulomatous change on histological examination was suggested as a criteria for CD diagnosis by a panel member.

\section{Statement 2.2 \\ Symptoms of CD are heterogeneous but commonly include ab- dominal pain and/or chronic diarrhea in addition to weight loss. These symptoms should raise the suspicion of $C D$, especially in young patients. \\ - Level of agreement: strongly agree 90\%, agree 10\%, disagree 0\%}

The most common symptoms present in patients with CD prior to diagnosis are diarrhea and abdominal pain, both of which are significantly more common as prodromal symptoms in CD than in UC. ${ }^{46}$ Weight loss is also a common prodromal symptom in CD that is typically not seen in UC. ${ }^{46}$ Diarrhea (increased stool frequency and decreased stool consistency) with a duration of at least 4 weeks is unlikely to be of a self-limiting infectious cause, and chronic noninfectious etiologies should be considered. ${ }^{47}$ The most common clinical scenario of CD is a young patient presenting with chronic diarrhea, right lower quadrant abdominal pain, and weight loss. ${ }^{1}$ Smoking and family history of IBD are well-proven risk factors and their presence should further 
raise the suspicion of $\mathrm{CD}^{48,49}$ Rectal bleeding or bloody diarrhea may be the major symptoms in patients with colonic involvement. ${ }^{1}$ Patients with perianal disease tend to be younger (median age, 37 years); ${ }^{50}$ therefore, CD should be suspected in young patients exhibiting perianal swelling and purulent discharge.

Initial examination should include evaluation of general wellbeing; perineal and oral inspection; rectal digital examination; measurement of pulse rate, blood pressure, and body temperature; and checking for abdominal tenderness or distension and palpable masses. ${ }^{10}$ Measurement of body weight and calculation of BMI are recommended. Frequency of bowel movements and presence of bloody stool should be recorded. Level of education, occupation, and travel history should be noted. Detailed medication and allergy history should be obtained. Patients should be asked about nocturnal symptoms, extraintestinal manifestations (involving the mouth, skin, eye, or joints), perianal abscess, and anal fissure. ${ }^{10}$ Scoring of disease activity using the CDAI, or pediatric CDAI if appropriate, should be performed before initiation of therapy. ${ }^{51-53}$ Routing genetic testing is not recommended in the work-up of CD patients.

\section{Statement 2.3 \\ Ileocolonoscopy with biopsies of the terminal ileum and each co- Ionic segment to identify microscopic evidence of $C D$ is the first- line procedure for establishing the diagnosis. \\ - Level of agreement: strongly agree, 58.3\%, agree 41.7\%, dis- agree $0 \%$}

Ileocolonoscopy with multiple mucosal biopsies is the first-line procedure for establishing $\mathrm{CD}$ diagnosis. ${ }^{10,12} \mathrm{Bi}$ opsies from at least 5 sites in the terminal ileum and colon (ascending, transverse, and sigmoid colon and rectum), including from both endoscopically normal and abnormal areas, should be taken. ${ }^{12,54}$ Further investigation to examine the location and extent of CD in the small bowel is recommended regardless of ileocolonoscopy findings. ${ }^{10}$ The value of colonoscopy must be weighed against the risk of bowel perforation, which is increased with severe active disease. ${ }^{55}$

\footnotetext{
Statement 2.4

The endoscopic features which suggest a diagnosis of CD include segmental lesions, anorectal lesions, longitudinal ulcers, aphthous ulcers, and a cobblestone appearance.

- Level of agreement: strongly agree $53.8 \%$, agree $46.2 \%$, disagree $0 \%$
}

The earliest and most characteristic endoscopic finding in CD are aphthous ulcers, which are small punched-out ulcers in an otherwise endoscopically normal mucosa ${ }^{56,57}$ Ulcers enlarge, coalesce, and deepen as disease severity increases. Inflammation in CD is often discontinuous and adjacent to normal tissue, resulting in segmental lesions. ${ }^{10} \mathrm{~A}$ cobblestone appearance occurs when ulcers course longitudinally through areas of normal or inflamed tissue. ${ }^{56,57}$ Rectal sparing is typical and circumferential, and continuous inflammation is rare in $\mathrm{CD} .^{10}$ The Crohn's Disease Endoscopic Index of Severity (CDEIS) or the Simple Endoscopic Score for Crohn's Disease (SES-CD) should be utilized when CD is diagnosed or suspected by ileocolonoscopy to classify disease activity. ${ }^{58,59}$ SES-CD is more clinically practical and is the preferred endoscopic scoring system. ${ }^{60}$

\section{Statement 2.5}

The biopsy specimen for diagnosis of CD should also be evaluated for intestinal tuberculosis (TB). The appropriate tests include acidfast staining, TB culture, and TB PCR alone or in combination, depending on availability.

- Level of agreement: strongly agree $76.9 \%$, agree $23.1 \%$, disagree $0 \%$

As Taiwan is a TB-endemic region, intestinal TB should be considered as a differential diagnosis. ${ }^{61}$ Initiation of treatment with corticosteroids, immunosuppressants, or biologic agents in patients with intestinal TB misdiagnosed as CD can lead to worsening of TB disease ${ }^{62,63} \mathrm{CD}$ and intestinal TB have similar manifestations and endoscopic features; therefore, TB-specific testing should be performed. ${ }^{63}$ Many PCR-based tests for TB may be suboptimal, however, and interferon-gamma release assays (IGRA) should also be considered. ${ }^{12}$

\footnotetext{
Statement 2.6

Upper-gastrointestinal endoscopy is suggested in CD patients for clarifying the location of involvement.

- Level of agreement: strongly agree 60\%, agree 40\%, disagree $0 \%$
}

Although CD typically involves the terminal ileum, any part of the gastrointestinal tract can be affected. ${ }^{64}$ Upper gastrointestinal involvement can occur in patients with CD irrespective of the presence of upper gastrointestinal symptoms. ${ }^{65}$ Upper-gastrointestinal endoscopy findings characteristic of CD include a bamboo joint-like appearance, notch-shaped appearance, cobblestone appearance, multiple aphthous ulcerations, erosions, irregularly-shaped ulcers, bead-like protrusions, nodular folds, granular mucous membrane, and stenosis. ${ }^{15}$

The use of upper-gastrointestinal endoscopy in asymp- 
tomatic patients is debatable, nevertheless, it can clarify the location of involvement, particularly in patients with undifferentiated IBD by ileocolonoscopy, and can provide further details for use in Montreal classification. ${ }^{12,66}$ Moreover, upper-gastrointestinal endoscopy can identify gastritis of other etiologies. ${ }^{67}$ In a prospective study evaluating upper-endoscopy in the diagnostic work-up $\mathrm{CD}$, endoscopic evaluation revealed upper gastrointestinal tract CD in $16 \%$ of patients, Helicobacter pylori-related gastritis in $9 \%$, and focally active chronic gastritis in $29 \%{ }^{65}$

\section{Statement 2.7 \\ Small bowel endoscopy (capsule or enteroscopy) is indicated for patients with high suspicion for $C D$ despite inconclusive results of ileocolonoscopy and radiological imaging. \\ - Level of agreement: strongly agree $73.3 \%$, agree $26.7 \%$, dis- agree $0 \%$}

The small bowel, which is inaccessible to standard ileocolonoscopy, is involved in at least $70 \%$ of patients with $\mathrm{CD}^{6}$ Small-bowel capsule endoscopy has high sensitivity for detecting mucosal inflammation and has a superior diagnostic yield over other modalities for diagnosing CD, including CT and magnetic resonance (MR) enterography. ${ }^{68-70}$ Prior to performing capsule endoscopy, a patency capsule or radiographic imaging should be used to exclude the presence of strictures, which can lead to capsule retention. ${ }^{71}$ Device-assisted enteroscopy, such as single and double balloon enteroscopy, enables histopathologic confirmation when results of other diagnostic modalities, including small-bowel capsule endoscopy, are inconclusive. ${ }^{72,73}$ Device-assisted enteroscopy is more invasive and labor-intensive than small-bowel capsule endoscopy; however, the procedure can also be used to obtain biopsies and deliver therapeutic intervention. ${ }^{73}$

\footnotetext{
Statement 2.8

Radiological imaging studies are complementary to endoscopic evaluation in CD. CT and MRI are useful in detecting intestinal inflammation, strictures, and penetrating complications. Luminal distension is preferred.

- Level of agreement: strongly agree 65\%, agree 35\%, disagree $0 \%$
}

Cross-sectional imaging in addition to endoscopy provides more complete staging of the small bowel by allowing detection of mural and extramural involvement and penetrating lesions. ${ }^{10} \mathrm{CT}$ and MR enterography/enteroclysis are the imaging modalities with the highest diagnostic accuracy and are the current standards for evaluating the small intestine. ${ }^{10,74}$ Contrast agents for CT and MRI can be administered orally (enterography) or by nasojejunal tube (enteroclysis). Adequate luminal distension is a requirement for quality imaging of the small intestine as collapsed bowel loops can interfere with visualization. ${ }^{74}$

CT enteroclysis results in better distension of the proximal and distal jejunum and higher quality images than with CT enterography, but is more time consuming, invasive, causes more patient discomfort, and requires increased radiation dose. ${ }^{74}$ Sensitivity, specificity, and diagnostic accuracy for CD findings are comparable between the 2 methods, however, and CT enterography can be a valid alternative examination to CT enteroclysis. ${ }^{74}$ MR enterography/enteroclysis has similar diagnostic accuracy to $\mathrm{CT}^{10}$ Although MRI is more time consuming and less commonly available than CT, it is not associated with radiation exposure, which is the major limitation with $\mathrm{CT}^{74,75}$

Abdominal ultrasound is noninvasive, does not involve radiation exposure, and can be particularly useful for visualizing the terminal ileum and colon. ${ }^{74}$ Patients should fast for at least 6 hours prior to ultrasound examination to avoid impairment by gas. Contrast-enhanced ultrasound is a better predictor of inflammatory activity than baseline ultrasound, and unlike CT or MRI, allows real-time assessment of bowel wall perfusion. ${ }^{76}$ Nonetheless, ultrasound is a highly operator-dependent tool.

Barium small bowel follow-through examination is wellestablished and widely available at low cost, and is historically the most commonly performed evaluation of the small bowel. ${ }^{77}$ Though small bowel follow-through is similarly capable of detecting active disease in the small bowel compared with CT and MRI, it is less reliable for detecting extramural complications; therefore, alternative investigations are preferred. ${ }^{10,78}$

\footnotetext{
Statement 2.9

Radiation exposure should be a concern when selecting image modalities.

- Level of agreement: strongly agree $50 \%$, agree $50 \%$, disagree $0 \%$
}

Patients with CD typically undergo repeated imaging examinations beginning at a young age; therefore, the possibility of increased risk of life-time radiation-induced malignancy is of concern. ${ }^{79}$ In patients with IBD, radiation from CT imaging accounts for the majority of the total radiation dose received. ${ }^{80}$ While radiation exposure from barium studies is lower than that of CT, it may still pose a significant exposure when repeated examinations are performed. ${ }^{81}$ Although more costly and time consuming, MRI does not subject pa- 
tients to ionizing radiation, and should be considered as the preferred modality if available, especially in patients who require frequent follow-up imaging. ${ }^{78}$

\section{Statement 2.10}

One major role of pathology in the diagnosis of CD is to help exclude other possibilities, such as infection and malignancy.

- Level of agreement: strongly agree 55\%, agree 45\%, disagree $0 \%$

The histological diagnosis of CD is based on architectural change and inflammatory status of the lesions. ${ }^{82}$ Mucosal architectural changes include glandular distortion (such as crypt branching, shortening, or widening or irregular mucosal surface), mucin and goblet cell depletion, Paneth cell metaplasia, and fissuring ulcer. ${ }^{83}$ Biopsy samples should also be evaluated for dysplasia. Assessment of inflammatory status in IBD should include detection of neutrophilic infiltrate, basal plasmacytosis, eosinophilic infiltrate, and granulomas. ${ }^{54}$ Due to the discontinuity of inflammation and the possibility of biopsy error, clinical findings must be taken into consideration in the histopathological diagnosis of $\mathrm{CD}^{84}$

Histological distinction between UC and CD can be difficult, and patients may be given an intermediate diagnosis of "indeterminate colitis." Lymphoma and infectious colitis (TB infection, amebiasis, cytomegalovirus infection, and pseudomembranous colitis) should be excluded on histological examination before the diagnosis of IBD can be made. The presence of adenocarcinoma should also be included in the pathology report. The committee recommends the use of a checklist for use during histological assessment to support thorough evaluation and accurate diagnosis (Fig. 1). It is also suggested that previous biopsy slides be reviewed and assessed upon diagnosis of CD.

\section{Specific Considerations}

\section{Statement 3.1}

$\mathrm{HBsAg}$, hepatitis B surface antibody ( $\mathrm{HBsAb})$, and hepatitis B core antibody $(\mathrm{HBCAb})$ should be routinely checked before treatment initiation, especially before the initiation of immunomodulating and immunosuppressive treatments such as steroids and biologics.

- Level of agreement: strongly agree $46.2 \%$, agree $53.8 \%$, disagree $0 \%$

In Asia, $\mathrm{HBV}$ infection is endemic, and prevalence in East Asia is the highest of all Asian regions. ${ }^{85}$ Over $8 \%$ of males over 35 years of age are positive for HBsAg in East Asia. ${ }^{85}$ Screening for HBV should be done prior to the initiation of immunomodulating/immunosuppressive therapy for CD to minimize the risk of acute HBV reactivation, which can be a life-threatening complication in patients with IBD. ${ }^{86,87} \mathrm{HBV}$ vaccination is recommended in patients who are negative for HBsAg, HBsAb, and HBcAb.

\section{Statement 3.2}

In patients who are HBsAg and/or HBcAb positive, HBV DNA quantification is recommended before the initiation of steroid or biologic treatment.

- Level of agreement: strongly agree $69.2 \%$, agree $30.8 \%$, disagree $0 \%$

In patients with IBD, $25 \%$ to $36 \%$ of those who are HBsAg positive experienced liver dysfunction. ${ }^{88,89}$ Most cases of HBV reactivation have been observed in HBV-infected IBD patients treated with 2 or more immunomodulating treatments for a long period of time, were positive for HBV DNA, and/or had not received prophylactic antiviral treatment. ${ }^{86}$

\section{Statement 3.3}

Antiviral treatment for prophylaxis of HBV reactivation is recommended in patients with detectable HBV DNA and should be discussed with the patient and family, or, at least, HBV DNA should be monitored closely and antiviral treatment initiated when increase in HBV DNA titer is observed.

- Level of agreement: strongly agree $53.8 \%$, agree $46.2 \%$, disagree $0 \%$

Treatment with nucleotide/nucleoside analogues as

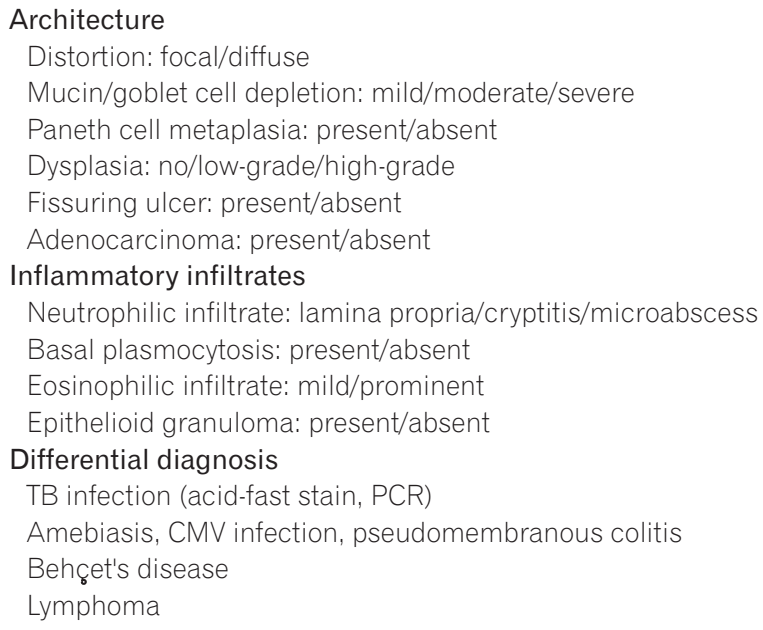

Fig. 1. Recommended checklist for use during histological assessment of IBD. Use of this checklist during histological assessment is recommended to support thorough evaluation of mucosal architecture and inflammatory infiltrates and exclusion of differential diagnoses (disease activity scoring using the Nancy histological index is suggested only for patients with UC). TB, tuberculosis; CMV, cytomegalovirus. 
antiviral prophylaxis is recommended in patients with detectable HBV DNA. Prophylactic antiviral treatment should be started 2 weeks before initiation of immunomodulating therapy and continued for 6 to 12 months after its discontinuation. ${ }^{86}$ Entecavir and tenefovir have rapid onset of action, high antiviral potency, and low incidence of resistance, and are preferred in patients with IBD. ${ }^{86}$

\section{Statement 3.4 \\ Routine screening for latent TB infection with chest X-ray (and if available, IGRA) or tuberculin skin test (TST) is recommended before initiating biologic treatment in patients with CD. \\ - Level of agreement: strongly agree $83.3 \%$, agree $16.7 \%$, dis- agree $0 \%$}

Due to the use of immunomodulating treatments, patients with IBD are at higher risk of active TB infection than the general population. ${ }^{86}$ Moreover, TB presentation is more commonly atypical, extrapulmonary, and disserminated in patients treated with anti-tumor necrosis factor (anti-TNF), making diagnosis more difficult. ${ }^{86}$ In Taiwan, $5.8 \%$ of cases of extrapulmonary TB were reported to have occurred in the gastrointestinal tract. ${ }^{61}$ Screening for latent TB should be performed in all CD patients prior to biologic therapy through physical examination, chest radiography, and TST or IGRA (QuantiFERON-TB GOLD). It should be noted that results of TST could be affected by prior BCG vaccination, whereas IGRA is not. ${ }^{90}$

\section{Statement 3.5}

In patients diagnosed with latent $\mathrm{TB}$, prophylactic treatment for prevention of TB reactivation should be started at least 4 weeks before using biologics.

- Level of agreement: strongly agree $83.3 \%$, agree $16.7 \%$, disagree $0 \%$

Chemoprophylaxis is highly effectively in decreasing the risk of TB reactivation in patients with latent TB. Treatment of latent TB should follow the current guideline recommendations set forth by the Taiwan Centers for Disease Control. ${ }^{91}$ At least 4 weeks of TB treatment should be administered before initiating biologic therapy. Consultation with an infectious disease or chest specialist for multidisciplinary care is recommended.

\section{Statement 3.6}

During biologic therapy, patients should be monitored for signs and symptoms of active TB with chest X-ray and IGRA performed at least annually.

- Level of agreement: strongly agree $66.7 \%$, agree $33.3 \%$, disagree $0 \%$

Patients with IBD receiving biologic treatment should be monitored regularly for signs and symptoms of active TB disease. Chest radiography and IGRA should be performed ideally every 6 months, or at least annually in clinical practice for IGRA. ${ }^{61}$ Travel and TB contact history should be monitored while the patient is receiving immunosuppressive treatment. An infectious disease specialist should be consulted when necessary.

\section{Treatment}

\section{1) Therapeutic Considerations}

\section{Statement 4.1.1}

The treatment of CD must depend on the location and activity of disease.

- Level of agreement: strongly agree 93.3\%, agree 6.7\%, disagree $0 \%$

Disease location, activity, and behavior (inflammatory, structuring, or fistulizing) and presence of negative prognostic predictors (including young age at onset and positive smoking history) should be taken into account in the management of $\mathrm{CD} .{ }^{13}$ Severity of disease should be assessed using objective measures such as inflammatory markers and endoscopic indices. Scoring of disease activity using CDAI is required in the application for NHI reimbursement for biologic agents. Mild, moderate, and severe $\mathrm{CD}$ are equivalent to CDAI scores of 150 to 220,220 to 450 , and $>450$, respectively. ${ }^{10} \mathrm{CD}$ is considered to be in remission when $\mathrm{CDAI}$ is $<150$.

\section{Statement 4.1.2}

The goals of treatment include induction and maintenance of remission, prevention of strictures, fistula, and other complications, and improving quality of life.

- Level of agreement: strongly agree 93.3\%, agree 6.7\%, disagree $0 \%$

Therapeutic decisions should be tailored to the individual patient and aimed at inducing and maintaining remission, preventing complications, and improving quality of life, with consideration of balance between efficacy and toxicity and previous response to treatment. An accelerated progres- 


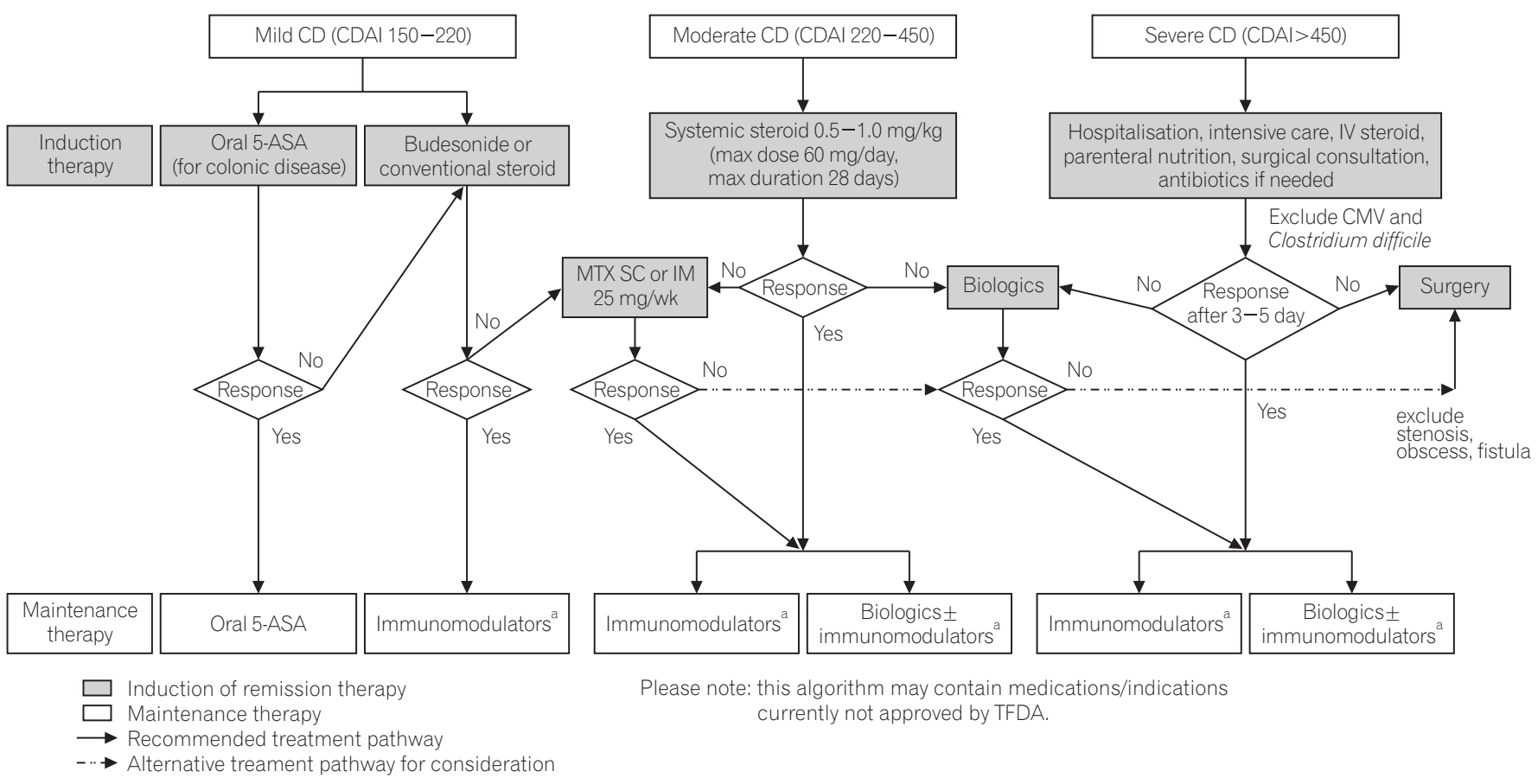

Fig. 2. Recommended algorithm for the treatment of $C D$. Treatment algorithm for patients with $C D$ developed through consensus of an expert panel established by the Taiwan Society of Inflammatory Bowel Disease. Recommendations were formulated after consideration of available evidence and expert opinion as well as the medical environment specific to Taiwan. Immunomodulators include methotrexate (MTX) and thiopurines (azathioprine [AZA] and 6-mercaptopurine [6-MP]). IV steroid treatment consists of methylprednisolone $60 \mathrm{mg} /$ day or hydrocortisone $100 \mathrm{mg} 4$ times daily. Biologics include infliximab, adalimumab, golimumab, and vedolizumab among others. ${ }^{~} \mathrm{MTX}$ maintenance dosage: $10-15 \mathrm{mg} / \mathrm{wk}$. 5-ASA, 5-aminosalicylic acid (mesalamine); IV, intravenous; CMV, cytomegalovirus; IM, intramuscular; TFDA, Taiwan Food and Drug Administration.

sive approach, which entails rapid escalation of treatment if no adequate response is achieved within an expected time frame, is the current recommended practice. ${ }^{10}$ The $\mathrm{CD}$ treatment algorithm recommended by the committee is presented in Fig. 2.

\section{2) Induction Therapy in Mild CD}

\author{
Statement 4.2.1 \\ Aminosalicylates (5-ASA) can be used in mild CD. \\ - Level of agreement: strongly agree $73.3 \%$, agree $26.7 \%$, dis- \\ agree $0 \%$
}

Oral 5-ASA preparations were shown to be effective in active ileal or ileocolonic CD in earlier clinical trials. ${ }^{92-95}$ More recently, however, meta-analysis of 3 controlled trials found only a nonsignificant trend in favor of sulfasalazine over placebo for inducing remission in CD (RR, 1.38; 95\% CI, 1.00-1.89; $P=0.05$ ), with benefit confined to patients with Crohn's colitis. ${ }^{96}$ Slow-release mesalamine was significantly superior to placebo in reducing CDAI score in patients with mild-to-moderate CD in a meta-analysis of 3 trials; however, the mean difference in CDAI score was only 63 points, a dif- ference which may not be considered clinically relevant. ${ }^{97}$ Although 5-ASA has shown only modest efficacy, treatment is well-tolerated with a rate of adverse events comparable to that of placebo. ${ }^{96}$ The committee recommends the use of oral 5-ASA as an option for induction therapy in patients with mild colonic disease.

\section{Statement 4.2.2}

Conventional steroids or budesonide are more effective than 5-ASA for inducing remission.

- Level of agreement: strongly agree $73.3 \%$, agree $26.7 \%$, disagree $0 \%$

In a pooled analysis of $260 \mathrm{CD}$ patients from 2 studies, sulfasalazine was less effective than corticosteroids at inducing remission. ${ }^{96}$ At 18 weeks of follow-up, $43 \%$ of sulfasalazine patients entered remission compared to $60 \%$ of corticosteroid patients (RR, 0.68; 95\% CI, 0.51-0.91). Trials comparing delayed-release mesalamine with conventional corticosteroids have found no significant difference in efficacy. ${ }^{98-100}$ In a trial including patients with active $\mathrm{CD}$ limited to the distal ileum and ascending colon, mesalamine was less effective for inducing remission at 16 weeks compared with 
budesonide (36\% mesalamine group vs. $62 \%$ budesonide group, $P<0.001) .{ }^{101}$ Compared with conventional steroids, budesonide was less effective for induction of remission in a meta-analysis of 8 trials (RR, 0.85 ; 95\% CI, 0.75-0.97), but significantly fewer side effects occurred in those treated with budesonide compared to conventional steroids (RR, 0.64; 95\% CI, 0.54-0.76). ${ }^{102}$ Current evidence suggests that budesonide $9 \mathrm{mg} /$ day is the preferred induction treatment in mild active ileocecal $\mathrm{CD} ;{ }^{10}$ however, budesonide is currently not available in Taiwan.

\section{3) Induction Therapy in Moderate-to-Severe Active CD}

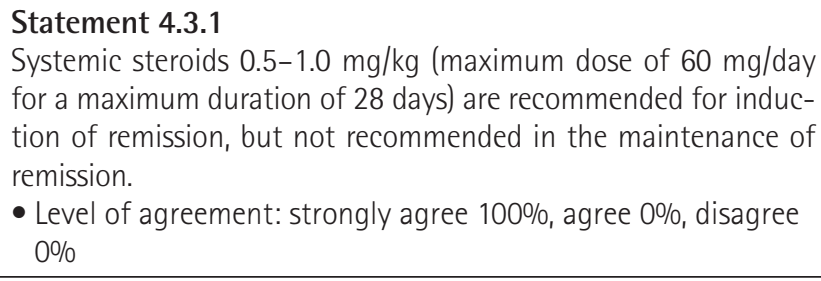

Patients with moderate disease should receive steroid treatment until resolution of symptoms and resumption of weight gain. ${ }^{14}$ Conventional corticosteroids are more effective than 5-ASA for inducing CD remission in studies with follow-up duration longer than 15 weeks (RR, 1.65; 95\% CI, 1.33-2.03) ${ }^{103}$ Although steroids are the mainstay for initial treatment of active disease, steroid exposure should be minimized.$^{10}$ In pooled analyses, no difference was found between steroids, including budesonide, and placebo for maintenance of remission in patients with $\mathrm{CD}^{103,104}$

\section{Statement 4.3.2}

Methotrexate (MTX) is effective for inducing remission in steroiddependent and steroid-refractory CD.

- Level of agreement: strongly agree $60 \%$, agree $40 \%$, disagree $0 \%$

MTX is effective in patients who relapse when steroids are withdrawn. ${ }^{105}$ In a controlled trial of $141 \mathrm{CD}$ patients who had chronically active CD despite at least 3 months of prednisone therapy, patients treated with intramuscular MTX $25 \mathrm{mg}$ weekly were significantly more likely to be in clinical remission at 16 weeks than those receiving placebo (RR, 1.95; 95\% CI, 1.09-3.48). ${ }^{106}$ Alternatively, MTX can be administered SC. ${ }^{10}$ Doses $<15 \mathrm{mg} / \mathrm{wk}$ and oral administration of MTX are not effective for active CD. ${ }^{105}$

\section{Statement 4.3.3}

Biologics are effective for inducing remission in patients with moderate-to-severe active $C D$ who do not respond to treatment with steroids, thiopurines, or MTX.

- Level of agreement: strongly agree 86.7\%, agree 13.3\%, disagree $0 \%$

Biologic treatments have demonstrated efficacy as induction therapy in active $\mathrm{CD}$ in multiple controlled trials. ${ }^{107-116} \mathrm{In}$ 108 patients with moderate-to-severe CD refractory to steroids or 5-ASA, 33\% of patients treated with a single infusion of infliximab achieved remission compared with $4 \%$ with placebo. ${ }^{107}$ In the CLASSIC I trial, remission was achieved in $36 \%$ of patients receiving adalimumab and $12 \%$ of those receiving placebo. ${ }^{109}$ In patients treated with adalimumab following infliximab failure, $21 \%$ achieved remission compared with $7 \%$ of patients on placebo in the GAIN trial. ${ }^{112}$ Vedolizumab is a gut-selective $\alpha 4 \beta 7$ integrin antagonist that was shown to be efficacious for the treatment of moderateto-severe active CD in the GEMINI trials. ${ }^{113,114}$ Remission was induced in $14.5 \%$ of patient receiving vedolizumab versus $6.8 \%$ of those receiving placebo at week $6 .{ }^{113}$ Post hoc analyses demonstrated clinical benefit of vedolizumab in both anti-TNF-naïve and anti-TNF-failure patients, though patients who were naïve to anti-TNF therapy experienced a higher rate of response. ${ }^{115}$ In 2 induction trials, the novel biologic agent ustekinumab, a fully humanized monoclonal antibody to the p40 subunit of interleukin-12 and interleukin-23, has shown benefit in patients with CD refractory to anti-TNF (UNITI-1 trial) or conventional (UNITI-2 trial) agents. ${ }^{116}$ Response rates at week 6 were significantly higher with ustekinumab at a dose of either $130 \mathrm{mg}$ or approximately $6 \mathrm{mg} / \mathrm{kg}$ than with placebo in both trials (UNITI-1, $33.7 \%-34.3 \%$ with ustekinumab vs. $21.5 \%$ with placebo, $P \leq 0.003$; UNITI-1, $51.7 \%-55.5 \%$ with ustekinumab vs. $28.7 \%$ with placebo, $P \leq 0.001)$.

\section{4) Maintenance Therapy in CD}

\section{Statement 4.4.1 \\ Thiopurines (azathioprine [AZA] and 6-mercaptopurine [6-MP]) and MTX are effective for maintaining remission. \\ - Level of agreement: strongly agree 92.9\%, agree 7.1\%, dis- agree 0\%}

A pooled analysis of 6 studies showed that AZA was significantly superior to placebo for maintenance of remission, with $73 \%$ of patients in the AZA group maintaining remission compared to $62 \%$ of placebo patients (RR, 1.19; $95 \%$ 
CI, 1.05-1.34); however, the overall quality of the evidence was considered low due to sparse data and unclear risk of bias. ${ }^{117}$ Although no large study has specifically evaluated maintenance of remission with 6-MP, the drug is considered equivalent to AZA. ${ }^{10}$ Moderate quality evidence indicates that intramuscular MTX at a dose of $15 \mathrm{mg} / \mathrm{wk}$ is superior to placebo for maintenance of remission in CD (RR, 1.67; 95\% CI, 1.05-2.67). ${ }^{118}$ Currently, no trial has compared AZA and intramuscular MTX for maintenance therapy in CD.

\section{Statement 4.4.2}

Biologics with or without immunomodulators (AZA, 6-MP, and MTX) are effective for maintaining remission.

- Level of agreement: strongly agree $71.4 \%$, agree $28.6 \%$, disagree $0 \%$

In 2 meta-analyses, anti-TNF therapy was more effective than placebo for maintaining remission. ${ }^{119,120}$ Compared with placebo, the RR of maintaining remission was 2.50 with infliximab (95\% CI, 1.64-3.80), 2.86 with adalimumab (95\% CI, 2.01-4.02), and 1.68 with certolizumab (95\% CI, 1.30-2.16). ${ }^{120}$ In a trial including patients who had a response to vedolizumab induction therapy, $36.4 \%$ to $39.0 \%$ were in clinical remission at week 52 with vedolizumab maintenance therapy compared to $21.6 \%$ with placebo $(P<0.05) .{ }^{113}$ In patients who had a clinical response to ustekinumab induction therapy, significantly higher remission rates at week 44 were found with SC ustekinumab maintenance therapy every 8 weeks (53.1\%) or 12 weeks (48.8\%) than with placebo $(35.9 \%$, $P=0.005$ and $P=0.04$, respectively). ${ }^{116}$

The evidence supporting the use of biologic agents in combination with immunomodulators is mixed. In a randomized controlled trial of patients in remission on infliximab treatment in combination with AZA, 6-MP, or MTX for at least 6 months, results could not show or exclude a beneficial effect of continued combination therapy over withdrawal of immunomodulator. ${ }^{121}$ In the Diamond study conducted in Japan, clinical remission rate did not differ between the adalimumab monotherapy group and the combination adalimumab and AZA group at week 26 (71.8\% vs. $68.1 \%$, respectively; OR, $0.84 ; P=0.63$ ) in patients with active $C D$ who were naïve to biologics and thiopurines. ${ }^{122}$ In contrast, results from the SONIC trial showed a significantly higher rate of corticosteroid-free clinical remission at week 26 with combination infliximab and AZA (56.7\%) than with infliximab alone (44.4\%) or AZA alone $(30.0 \%)$ in patients with moderate-to-severe $\mathrm{CD}$ who were naïve to immunomodulating and anti-TNF agents. ${ }^{123}$ While combination biologic and immunomodulat- ing therapy may improve treatment efficacy, the risk of infection and malignancy may also be increased. ${ }^{124}$

\section{5) Management of Severe, Complicated Active CD}

\section{Statement 4.5.1}

Hospitalization, intensive care, and a multidisciplinary approach are highly recommended for severe active $C D$.

- Level of agreement: strongly agree 100\%, agree 0\%, disagree $0 \%$

Patients with severe, complicated active CD should be hospitalized for intensive care. Antibiotics should be administered if the patient has perianal disease or complications from bacterial overgrowth. ${ }^{10}$ Parenteral nutrition is appropriate as supportive care. To optimize patient outcome, management should involve a multidisciplinary team including specialists of gastroenterology, surgery, and other disciplines.

Initial treatment for severe CD should be intravenous steroids equivalent to methylprednisolone $60 \mathrm{mg}$ daily or hydrocortisone $100 \mathrm{mg} 4$ times daily. Biologic treatment should be used in patients not responding to initial steroid treatment (see Statement 4.3.3).

\section{Statement 4.5.2}

Early surgical consultation is suggested when results of medical treatment are unsatisfactory.

- Level of agreement: strongly agree 92.9\%, agree 7.1\%, disagree $0 \%$

Surgery is indicated for patients with severe CD who fail to respond to medical treatment or have worsening symptoms. ${ }^{14}$ In patients who are candidates for surgery, early surgery is preferred as prolonged immunosuppressive treatment may increase the risk of surgical complications such as sepsis and impaired healing. ${ }^{125}$ In addition, early surgery has been associated with reduced risk of clinical recurrence compared to surgery performed late in the course of $\mathrm{CD} .{ }^{126}$

\section{Monitoring}

\section{1) Endoscopy}

\section{Statement 5.1.1}

Achieving mucosal healing with CD therapy is associated with an improved clinical outcome.

- Level of agreement: strongly agree 95\%, agree 5\%, disagree $0 \%$ 
In CD, mucosal healing is associated with longer relapsefree survival, higher steroid-free remission rates, and fewer disease-related hospitalizations and surgeries. ${ }^{127,128}$ Mucosal healing is a critical component of outcome measurement in trials evaluating CD treatment, and has been commonly defined as the absence of mucosal ulceration or a CDEIS or SES-CD score of $0 .{ }^{128-130}$ Routine annual endoscopy for patients in clinical remission is unnecessary, however, unless a change in management is expected from the findings. ${ }^{127}$

\section{Statement 5.1.2}

Endoscopy is the gold standard in the diagnosis of postoperative recurrence. Findings define the severity of lesions and help predict the clinical course. Endoscopic evaluation is recommended 6 to 12 months after surgery to help guide treatment decisionmaking.

- Level of agreement: strongly agree $40 \%$, agree $60 \%$, disagree $0 \%$

Recurrence of CD after surgical resection is common and typically develops during the first postoperative year. ${ }^{131,132}$ The gold standard procedure to diagnose recurrence after surgery is endoscopy, as it has been shown to be the most sensitive modality to detect morphologic recurrence, and should be performed 6 to 12 months after surgery where treatment decisions may be affected. ${ }^{11}$ Signs of recurrence can be observed endoscopically before clinical symptoms appear. ${ }^{131,133}$ The Rutgeerts scoring system, which was developed to predict postoperative recurrence of $\mathrm{CD}$ in the terminal ileum, classifies patients into 5 groups (i0-i4) based on severity of endoscopic findings. ${ }^{134}$ Patients with a score of i0 or il (low risk) within 1 year of surgery have a 10-year recurrence rate of less than $10 \% .{ }^{134}$

\section{Statement 5.1.3 \\ Endoscopic reassessment should be considered in cases of relapse, refractoriness, new symptoms, or when surgery is considered. \\ - Level of agreement: strongly agree 95\%, agree 5\%, disagree $0 \%$}

Endoscopy objectively assesses disease activity and is a more reliable indicator of disease severity than subjective symptoms. ${ }^{135}$ Patients with loss of response to therapy, frequent relapse, or steroid dependency should be endoscopically reassessed if intensification of medical therapy or surgical intervention is considered. ${ }^{127,135}$

\section{2) Biochemistry Tests}

\section{Statement 5.2.1}

Full blood count, CRP level, ESR, and fecal calprotectin level could be measured for assessing gut inflammation and disease severity in $\mathrm{CD}$.

- Level of agreement: strongly agree $75 \%$, agree $25 \%$, disagree $0 \%$

No single laboratory test can fully assess disease activity in CD; therefore, measurement and consideration of multiple markers are recommended. The surrogate inflammatory markers CRP and ESR are elevated with active disease in CD. ${ }^{136,137}$ Serum CRP concentration has shown acceptable correlation with disease activity, though stronger association has been reported with colonic or ileocolonic disease location. ${ }^{137,138}$ Fecal calprotectin, a protein derived from neutrophils, is markedly elevated in infectious and inflammatory intestinal conditions, including IBD. ${ }^{139,140}$ Compared with CRP and ESR, which are not specific to intestinal diseases, fecal calprotectin has significantly greater sensitivity and specificity for predicting organic intestinal disease. ${ }^{141}$ In addition, fecal calprotectin effectively differentiates patients with IBD from those with IBS. ${ }^{141,142}$ Furthermore, fecal calprotectin level correlated well with endoscopic activity in IBD patients in a study conducted Taiwan. ${ }^{143}$

\section{Statement 5.2.2}

Serum level of CRP is helpful for evaluating response to therapy and assessing risk of relapse in CD.

- Level of agreement: strongly agree $76.2 \%$, agree $23.8 \%$, disagree $0 \%$

Studies have shown a good correlation between CRP level and clinical, histological, and endoscopic disease activity in CD. ${ }^{136,137,144}$ In Korean CD patients, CRP level was significantly correlated with CDAI; however, the correlation was weaker in patients with an ileal disease location. ${ }^{137} \mathrm{~A}$ decrease in CRP levels following therapy is objective evidence of reduction of inflammation, whereas elevated CRP levels may indicate therapy failure or presence of an infectious complication. ${ }^{10,145}$ In the prediction of clinical relapse, early normalization of CRP levels is associated with sustained long-term response to therapy, whereas elevated CRP levels are associated with a higher risk for relapse despite treatment. ${ }^{145,146}$ 


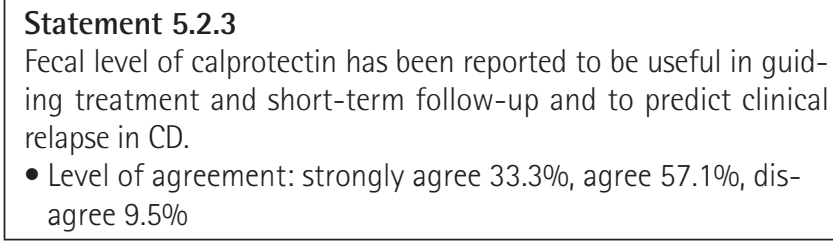

- Level of agreement: strongly agree $33.3 \%$, agree $57.1 \%$, disagree $9.5 \%$

Fecal calprotectin concentration is a useful assessment to estimate CD activity and monitor response to treatment as well as to predict remission and relapse. ${ }^{147,148}$ Fecal calprotectin is a more sensitive surrogate marker for predicting concurrent endoscopic CD activity than CDAI or CRP, with a fecal calprotectin concentration $\geq 200 \mu \mathrm{g} / \mathrm{g}$ having a $94 \%$ positive predictive value in predicting endoscopically active disease. ${ }^{149}$ In predicting remission and relapse, fecal calprotectin concentration $<130 \mu \mathrm{g} / \mathrm{g}$ is consistently associated with maintained disease remission, and a level $>300 \mu \mathrm{g} / \mathrm{g}$ is associated with a high probability of relapse. ${ }^{148}$

\section{3) Imaging}

\section{Statement 5.3.1}

Imaging studies, in particular MRI or CT enterography, can be used for monitoring treatment response of $\mathrm{CD}$.

- Level of agreement: strongly agree $55 \%$, agree $45 \%$, disagree $0 \%$

Studies evaluating change in radiologic parameters of active inflammation in response to treatment in CD are limited. Significant improvement in ultrasonographic parameters after treatment in patients with $\mathrm{CD}$ have been reported in prospective studies; however, correlation between ultrasound findings and clinical and biological response was variable. ${ }^{150,151}$ Cross-sectional imaging with CT or MRI can be used to quantify transmural structural damage and disease activity, particularly in the small bowel, and are also able to detect obstructive and penetrating complications. ${ }^{152}$ Several MR-based scoring systems have been evaluated for assessing CD, including the Magnetic Resonance Index of Activity score, the Crohn's Disease MRI Index, the Magnetic Resonance Enterography Global Score, and the Nancy score. ${ }^{153-156}$ Studies have shown significant correlation between MRI indexes and inflammatory parameters during treatment; however, MRI scoring is time-consuming, which may limit its use in routine clinical practice..$^{74,152}$

\section{4) Pathology}

Microscopic inflammation can be present in biopsy samples from tissue that appears free of inflammation on endoscopic examination; therefore, histological disease ac- tivity may be a better indicator for CD severity and extent. ${ }^{157}$ Inflammatory status of biopsy samples is the main monitoring parameter of $\mathrm{CD}$, but should always be considered in conjunction with patients' clinical presentation.

\section{Surgery}

\section{Statement 6.1}

Localized ileocecal CD with obstructive symptoms, but no significant evidence of active inflammation, could be treated by surgery.

- Level of agreement: strongly agree $83.3 \%$, agree $16.7 \%$, disagree $0 \%$

Primary surgery should be considered as the first-line intervention in patients with ileocecal CD presenting with obstruction without inflammation or those with refractory obstructive symptoms after initial steroid treatment. ${ }^{11} \mathrm{~Pa}-$ tients with active inflammation confined to the ileocecum without imminent obstruction can be treated with steroids, though will likely require surgery later on. ${ }^{11}$ Ileocecal resection results in a high rate of disease control with low morbidity. Results of long-term studies show that approximately half of CD patients who underwent ileocecal resection do not develop recurrence requiring further surgery. ${ }^{158,159}$ Therefore, delays in surgical management may unnecessarily prolong patients' disease state.

\section{Statement 6.2}

Terminal ileitis resembling CD found at a laparotomy for suspected appendicitis should not routinely be resected.

- Level of agreement: strongly agree $66.7 \%$, agree $33.3 \%$, disagree $0 \%$

The clinical presentation of ileal CD may mimic acute appendicitis. ${ }^{160}$ Though incidence is rare, ileal CD should be considered during differential diagnosis for patients exhibiting inflammation of the terminal ileum on laparoscopy for a clinical suspicion of appendicitis. ${ }^{11,161,162}$ Small bowel diverticulitis should also be included in differential diagnosis as it can also cause similar nonspecific clinical symptoms and show CD-like histological findings. ${ }^{163,164}$ While surgery is appropriate for appendicitis and diverticulitis, resection might not be the most appropriate strategy for Crohn's ileitis. ${ }^{11,165}$

\section{Statement 6.3}

Active small bowel CD with a concomitant abdominal abscess should preferably be managed with antibiotics and percutaneous or surgical drainage followed by delayed resection if necessary.

- Level of agreement: strongly agree $83.3 \%$, agree $16.7 \%$, disagree $0 \%$ 
Percutaneous drainage and delayed resection is recommended for patients with active small bowel CD with a concomitant abdominal abscess and obstructive symptoms. ${ }^{125}$ Although randomized trials are lacking, results from retrospective studies have shown that antibiotic treatment with percutaneous drainage is successful in $74 \%$ to $100 \%$ of patients and may allow avoidance of surgery. ${ }^{166-168}$ If surgery is required, delayed surgery is associated with less morbidity, a lower stoma rate, and less extensive resection. ${ }^{169,170}$

\section{Statement 6.4}

All available evidence suggests that in patients with an unsuspected diagnosis of CD after ileal pouch-anal anastomosis (IPAA), there are higher complication and failure rates. At present, an IPAA is not recommended in patients with Crohn's colitis.

- Level of agreement: strongly agree $72.2 \%$, agree $27.8 \%$, disagree $0 \%$

IPAA is generally considered to be contraindicated in patients with CD or Crohn's colitis. ${ }^{171}$ In a meta-analysis of 10 studies comprising 3,103 patients, CD patients were found to develop more anastomotic strictures $(\mathrm{OR}, 2.12 ; 95 \% \mathrm{CI}$, 0.99-4.53) and experience pouch failure more frequently (OR, 7.87; 95\% CI, 3.37-18.39) than patients with UC or indeterminate colitis after IPAA. ${ }^{172}$

\section{Statement 6.5}

Prednisolone at dosages greater than $20 \mathrm{mg}$ daily or equivalent for more than 6 weeks is a risk factor for surgical complications. Therefore, corticosteroids should be weaned if possible.

- Level of agreement: strongly agree $77.8 \%$, agree $22.2 \%$, disagree $0 \%$

Multiple studies have reported preoperative corticosteroid use in patients with IBD to be associated with an increased risk of postoperative complications, particularly at doses equivalent to $20 \mathrm{mg}$ prednisolone daily or greater. ${ }^{173-175}$

\section{Statement 6.6}

All patients should be encouraged to quit smoking after surgery for CD. Absence of prophylactic treatment is associated with a higher risk of relapse.

- Level of agreement: strongly agree $83.3 \%$, agree $16.7 \%$, disagree $0 \%$

Current smoking has been consistently reported as a significant risk factor for surgery in $\mathrm{CD}$ as well as a predictor of early postoperative recurrence after ileocolonic resection. ${ }^{176,177}$ In a meta-analysis of 16 studies including 2,962 patients with CD, smokers had a 2.5 -fold risk of postoperative recurrence and a 2-fold risk of clinical recurrence compared to non-smokers. ${ }^{177}$ Patients with CD should be encouraged to stop smoking since no significant difference in relapse and surgical recurrence rates at 10 years was found between exsmokers and non-smokers. ${ }^{177}$ In addition to smoking, prior intestinal surgery, penetrating disease behavior, perianal location, and extensive bowel resection have also been shown to predict early postoperative recurrence. ${ }^{178}$

Prophylactic medical treatment after ileocolonic resection has been shown to be effective in reducing the risk of recurrence. ${ }^{179-181}$ Meta-analysis of 9 controlled trials showed that treatment with anti-TNF agents was more effective at preventing clinical and endoscopic postoperative recurrence than thiopurines or 5-ASA. ${ }^{181}$ Imidazole antibiotics have been shown to be effective for reducing the risk of postoperative recurrence; however, poor tolerance to these agents prevents long-term use. ${ }^{178}$

\section{Special Populations}

\section{1) Pregnancy and Breastfeeding}

\section{Statement 7.1.1}

Modification of treatment for IBD is usually not necessary in pregnant patients, with the exception of MTX, which is contraindicated in pregnancy.

- Level of agreement: strongly agree 85\%, agree 15\%, disagree $0 \%$

Active disease seems to pose greater risks to mother and fetus than pharmacological treatment to maintain remission. ${ }^{178}$ Results of cohort and retrospective studies suggest that use of AZA and 6-MP in IBD patients is not associated with excess rates of prematurity, spontaneous abortion, or congenital abnormalities, and should not be discontinued during pregnancy. ${ }^{182-185}$ The use of infliximab or adalimumab in pregnant IBD patients has not been associated with abnormal pregnancy outcomes; however, these reports were based on studies with a small number of subjects. ${ }^{186-190} \mathrm{~A}$ meta-analysis of 7 studies with a total of 2,200 pregnant women with IBD found 5-ASA preparations to be relatively safe in pregnancy with no more than a 1.16-fold increase in congenital malformations, a 2.38-fold increase in stillbirth, a 1.14-fold increase in spontaneous abortion, a 1.35-fold increase in preterm delivery, and a 0.93 -fold increase in low birth weight. ${ }^{191}$ 


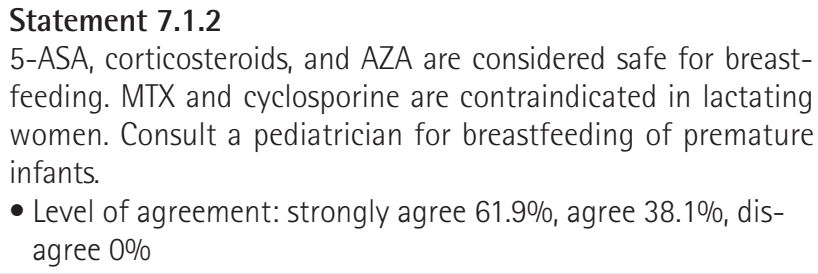

- Level of agreement: strongly agree $61.9 \%$, agree $38.1 \%$, disagree $0 \%$

5-ASA preparations and corticosteroids are considered safe for use while breastfeeding. The concentration of 5-ASA in the breastmilk of patients receiving 5-ASA therapy is low and considered clinically unimportant, though its metabolite is found in high levels in breastmilk. ${ }^{192}$ Although the metabolite is relatively inactive, it is advisable to avoid administering a high dose of 5-ASA to lactating women. Use of corticosteroids results in low concentrations of drug in breastmilk, and a 4-hour delay following oral dosing is recommended to reduce neonatal exposure. ${ }^{193}$ Infant exposure to AZA metabolites through breastmilk is undetectable. ${ }^{194}$ MTX and cyclosporine are contraindicated in breastfeeding. ${ }^{195}$ There is some evidence that exposure to breastmilk reduces the risk of development of early-onset IBD, which should be taken into consideration in the decision to breastfeed. ${ }^{196} \mathrm{Co}$ management with an obstetrician experienced in managing IBD is recommended.

\section{2) Pediatrics}

\section{Statement 7.2.1 \\ Oral corticosteroids are recommended for inducing remission in children with moderate-to-severe active luminal CD if exclusive enteral nutrition is not an option. Corticosteroids are not recom- mended as maintenance therapy. Growth curve should be moni- tored during the treatment course. \\ - Level of agreement: strongly agree $71.4 \%$, agree $28.6 \%$, dis- agree $0 \%$}

For remission induction of active pediatric $\mathrm{CD}$, a corticosteroid dose equivalent to oral prednisone $1 \mathrm{mg} / \mathrm{kg}$ once daily (up to $40 \mathrm{mg} /$ day) is recommended and may be increased to $1.5 \mathrm{mg} / \mathrm{kg}$ once daily (up to $60 \mathrm{mg} /$ day) if response is unsatisfactory. ${ }^{197}$ Intravenous administration of corticosteroids may be needed if oral corticosteroids fails. Growth during treatment should be monitored as use of corticosteroids in children is associated with retardation of growth. ${ }^{198}$

Data regarding the efficacy of immunomodulators as maintenance therapy in pediatric CD are sparse. In a multicenter randomized trial comparing combination 6-MP and prednisone with prednisone alone in pediatric CD patients, remission was induced in $89 \%$ of both groups; however, sig- nificantly fewer patients treated with added 6-MP relapsed compared with those treated with prednisone alone (9\% vs. $47 \%, P=0.007)$ and duration of steroid use was significantly shorter with the addition of 6-MP $(P<0.001) \cdot{ }^{199}$ Use of AZA in pediatric CD patients in Europe was associated with a longer maintenance of first remission compared with nonuse of AZA. ${ }^{200}$ AZA at a high dose of $3 \mathrm{mg} / \mathrm{kg}$ was shown to be safe and well-tolerated maintenance therapy for children with CD. ${ }^{201}$ For children refractory to or intolerant of thiopurines, MTX can effectively maintain remission. ${ }^{202}$ The effect on growth velocity from treatment with immunomodulators is unclear and emphasis should be put on nutritional therapy to maximize growth. ${ }^{201,202}$

\section{Statement 7.2.2}

Anti-TNF therapy is recommended for inducing and maintaining remission in children with chronically active luminal CD despite prior optimized immunomodulator therapy and in children with active perianal fistula in combination with appropriate surgical intervention.

- Level of agreement: strongly agree $66.7 \%$, agree $33.3 \%$, disagree $0 \%$

The efficacy of infliximab and adalimumab for induction and maintenance therapy in pediatric patients with refractory CD have been confirmed in randomized trials. ${ }^{203-205}$ At 1 year, $55.8 \%$ of anti-TNF-naïve pediatric CD patients achieved remission with infliximab and $45.1 \%$ achieved remission with adalimumab; however, the results cannot be compared due to differences in study design. ${ }^{205,206}$

Infliximab induction therapy should be administered at 5 $\mathrm{mg} / \mathrm{kg}$ at weeks 0,2 , and 6 , followed by maintenance therapy of $5 \mathrm{mg} / \mathrm{kg}$ every 8 weeks. ${ }^{197}$ Dose and interval adjustments may be needed according to response or to maintain drug level. Adalimumab induction therapy should be administered at $2.4 \mathrm{mg} / \mathrm{kg}$ (maximum $160 \mathrm{mg}$ ) at week $0,1.2 \mathrm{mg} / \mathrm{kg}$ (maximum $80 \mathrm{mg}$ ) at week 2 , followed by $0.6 \mathrm{mg} / \mathrm{kg}$ (maximum $40 \mathrm{mg}$ ) every other week. ${ }^{197}$

\section{Cancer Surveillance}

\footnotetext{
Statement 8.1

In patients with $C D$, adenocarcinoma complicating perianal or enterocutaneous fistula tracts can occur but is rare. Persistent chronic fistulas in long-standing CD, especially in young women, have been identified as potential risk factors for malignant transformation of fistula.

- Level of agreement: strongly agree $77.8 \%$, agree $22.2 \%$, disagree $0 \%$
} 
Fistula-associated adenocarcinomas can develop in patients with chronic perianal $\mathrm{CD}^{207,208}$ The incidence is very rare, however, and was reported at $0.2 / 1,000$ patient-years in CD patient in a meta-analysis of 20 clinical studies published from 1965 to $2008{ }^{209}$ Risk factors for malignant transformation include early disease onset, disease duration exceeding 10 years, chronic colitis with high inflammatory activity, and persistence of chronic fistulas and stenosis. ${ }^{210}$ In a systematic review of publications between 1950 and 2008, 61 cases of carcinomas arising in perineal fistulas in CD were identified, of which $61 \%$ were females. Moreover, females were significantly younger than males at cancer diagnosis, males had significantly longer duration of CD than females, and females had significantly shorter fistula duration prior to cancer transformation than males. ${ }^{211}$

Due to the nonspecific signs and symptoms of fistula-related cancer, diagnosis is often delayed and cancer may be of advanced stage at the time of diagnosis. Regular surveillance for ano-rectal cancer, including routine biopsy as needed, should be performed in all CD patients with perianal disease. ${ }^{212}$

\section{Statement 8.2}

Although it is not common, patients with CD involving the small bowel are at increased risk for small-bowel neoplasia.

- Level of agreement: strongly agree $82.4 \%$, agree $17.6 \%$, disagree $0 \%$

Adenocarcinomas are the most frequent small-bowel neoplasm in CD patients, usually arising in inflamed segments. ${ }^{212}$ Among patients with small bowel CD, the incidence rate of small-bowel adenocarcinoma has been reported to be $0.235 / 1,000$ patient-years. The incidence increased to $0.464 / 1,000$ patient-years among patients with duration of small-bowel CD greater than 8 years. ${ }^{213}$ Long-standing CD and stricturing disease are the risk factors most strongly associated with the development of small-bowel cancer in CD patients. ${ }^{212}$

In addition to small-bowel cancer, CD patients are at increased risk for upper gastrointestinal tract, lung, urinary bladder, lymphoma (particularly non-Hodgkin lymphoma) and non-melanoma skin cancer (NMSC) compared with the general population. ${ }^{214,215}$ Squamous-cell carcinoma and basal-cell carcinoma are the most common NMSCs occurring in patients with IBD. ${ }^{216,217}$

\section{Statement $\mathbf{8 . 3}$}

Patients with IBD treated with thiopurines are at increased risk for cancer, including lymphoma and NMSC.

- Level of agreement: strongly agree $82.4 \%$, agree $17.6 \%$, disagree $0 \%$

According to a nationwide population-based epidemiological study in Taiwan, patients with CD had an increased risk of hematological malignancies (standardized incidence ratio $[\mathrm{SIR}], 14.08 ; P<0.01$ ), non-Hodgkin's lymphoma (SIR, 14.29; $P<0.01$ ), and leukemia (SIR, $19.23 ; P<0.01$ ), especially in the first year, while the risk of NMSC was not increased. ${ }^{8} \mathrm{~A}$ meta-analysis of population-based studies found significantly increased incidence of lymphoma among IBD patients treated with thiopurines for longer than 1 year (SIR, 5.71; 95\% CI, 3.72-10.1). ${ }^{218}$ In particular, the risk of hepatosplenic T-cell lymphoma, a rare and usually fatal non-Hodgkin's lymphoma, is increased especially in men younger than 35 years with $\mathrm{CD}$ who have been treated with thiopurines for over 2 years. ${ }^{219}$ The excess risk of lymphoma seemed to be reversed after discontinuation of thiopurine therapy as risk was not increased in former users. ${ }^{218}$ In Taiwan, however, no significant difference was found regarding the occurrence of hematological malignancies between $\mathrm{CD}$ patients treated with or without immunomodulators. ${ }^{8}$

The risk of developing NMSC has been shown to be higher in patients with IBD receiving thiopurines than in the general population. ${ }^{220,221}$ A pooled adjusted hazard ratio for NMSC of 2.28 (95\% CI, 1.50-3.45) in IBD patients after exposure to thiopurines was revealed by a meta-analysis including 60,351 subjects. ${ }^{20}$ Past thiopurine exposure was identified as a significant risk factor for NMSC in a cohort study of 19,486 IBD patients; therefore, withdrawal of thiopurines may not reverse the excess risk for NMSC. ${ }^{222}$ Although NMSC has a much lower incidence in Asian countries and is of lesser concern than in Western countries, protection against sun exposure is recommended for patients receiving thiopurine treatment.

While the incidence of melanoma is not increased with thiopurine exposure in IBD patients, the use of anti-TNF agents was independently associated with an increased risk of melanoma in a cohort study including 108,579 patients with IBD (OR, 1.88; 95\% CI, 1.08-3.29) ${ }^{221}$ There is currently no evidence that anti-TNF monotherapy in patients with IBD increases the overall risk of cancer or the risk of lymphoma; however, it is unclear whether the risk of NMSC is increased with anti-TNF agents alone for IBD. ${ }^{212}$ 


\section{Complications}

\section{1) Fistulae}

\section{Statement 9.1.1}

The presence of a perianal abscess should be ruled out and if present should be drained as a matter of urgency.

- Level of agreement: strongly agree $89.5 \%$, agree $10.5 \%$, disagree $0 \%$

Management of simple perianal fistulae depends on whether the patient is symptomatic. Treatment is not needed if patients are asymptomatic. An underlying abscess is likely the cause of pain in patients with a simple perianal fistula and should be ruled out by examination under anesthesia and pelvic MRI or ano-rectal ultrasound. ${ }^{11}$ If an abscess is found, surgical treatment with a noncutting seton or fistulotomy is recommended in combination with antibiotics (metronidazole 750-1,500 mg/day or ciprofloxacin 1,000 $\mathrm{mg} /$ day).

\footnotetext{
Statement 9.1.2

AZA/6-MP, infliximab, adalimumab, seton drainage, or a combination of drainage and medical therapy should be used as maintenance therapy. Maintenance therapy should be used for at least 1 year.

- Level of agreement: strongly agree $78.9 \%$, agree $21.1 \%$, disagree $0 \%$
}

Active CD, especially with rectal inflammation, should be treated medically prior to surgery. A diverting stoma may be needed in patients with severe disease refractory to medical therapy. Maintenance therapy after successful cessation of fistula drainage is considered mandatory for complex perianal fistulae. The preferred medical therapy is AZA/6-MP, infliximab, or adalimumab as scheduled retreatment for at least 1 year, depending on the agent needed to induce remission. ${ }^{11}$

\section{2) Stenosis}

\section{Statement 9.2.1}

Anti-inflammatory therapy should only be considered if the stenosis has an inflammatory component.

- Level of agreement: strongly agree 78.9\%, agree $21.1 \%$, disagree $0 \%$

Over one-third of CD patients develop fibrostenosing CD, which is characterized by progressive narrowing of the bowel lumen caused by fibrosis. ${ }^{223}$ There is currently no specific medical therapy to treat fibrotic intestinal strictures. Patients with fibrostenosing CD should undergo evaluation to assess the presence of inflammation in the stricture. Anti-inflammatory treatments, including steroids, immunosuppressive drugs, and biologic agents, may relieve inflammatory lesions and related symptoms but do not prevent or reverse fibrosis. ${ }^{223-225}$

\section{Statement 9.2.2 \\ Endoscopic balloon dilation, strictureplasty, and intestinal resec- tion are reasonable treatment options for symptomatic short fibrotic strictures. \\ - Level of agreement: strongly agree $89.5 \%$, agree $10.5 \%$, dis- agree $0 \%$}

Endoscopic balloon dilation, strictureplasty, and resection are equivalent treatment options for the management of short stricture, generally defined as a stricture with length of $\leq 5 \mathrm{~cm} .{ }^{223,226}$ In a pooled analysis of 1,463 patients with $\mathrm{CD}$, endoscopic balloon dilation of strictures was successful in approximately $90 \%$ of cases, with a $73.5 \%$ chance for redilation and a $42.9 \%$ chance for surgical intervention within 24 months. ${ }^{226}$ Furthermore, stricture length of $\leq 5 \mathrm{~cm}$ was significantly associated with a surgery-free outcome (HR, 2.5; 95\% CI, 1.4-4.4). Endoscopic dilation and strictureplasty are contraindicated when an abscess, phlegmon, fistula, high-grade dysplasia, or malignancy is associated with the stenosis. ${ }^{223}$

\section{Statement 9.2.3}

Early surgery should be the preferred option for longer CD strictures in symptomatic patients.

- Level of agreement: strongly agree 94.4\%, agree 5.6\%, disagree $0 \%$

In patients with symptomatic stricturing disease in whom endoscopic dilation is unsuitable, including those with a stricture $>5 \mathrm{~cm}$ in length, early surgical resection is recommended. ${ }^{223,226,227}$ Compared with prolonged medical treatment, resection of isolated ileocecal disease in high-risk patients at diagnosis is associated with fewer subsequent complications, longer clinical remission, less need for medical therapy, lower risk of repeat surgery, and a longer time to surgical recurrence. ${ }^{126,223,228}$ Rate of repeat surgery has been reported to be $10 \%$ at 5 years and $15 \%$ to $20 \%$ at 10 years after ileocolic resection. ${ }^{229,230}$

Patients with colonic stricture are at significantly higher risk of colorectal cancer than patients without stricture and should receive careful surveillance. ${ }^{231}$ A population-based study found the rate of colorectal cancer in patients with colonic stricture at diagnosis to be approximately $5 \%$ at 10 years. ${ }^{232}$ The diagnosis and management of CD-related stricture has been extensively reviewed by Chang et al. ${ }^{233}$ 


\section{CONCLUSIONS}

These statements on the diagnosis and management of $\mathrm{CD}$ in Taiwan were developed through consensus of an expert panel established by TSIBD with consideration of available evidence, expert opinion, and factors specific to Taiwan, including endemic diseases, availability of treatments, and treatment coverage by NHI. The recommended treatment algorithm was developed with the aim of providing a concise and practical tool for supporting clinicians in Taiwan in their clinical decision making.

Thorough assessment of clinical, endoscopic, and histological findings and careful exclusion of differential diagnoses are required for accurate diagnosis of CD. Treatment is dictated by severity of disease, and generally consists of corticosteroids for induction of remission followed by maintenance with immunomodulators and/or biologics. Patients with severe disease that is refractory to medical treatment are candidates for surgery, which should not be unduly delayed. The current recommendations may require future revision as new data emerges for existing and novel therapies for the treatment of CD.

\section{ACKNOWLEDGEMENTS}

We would like to express our appreciation to all $27 \mathrm{mem}$ bers of the expert panel for their devotion to the development of these guidelines. Special thanks to J.W.C., H.H.L., W.C.L., and T.H.C. for their rigorous review of the draft and S.C.W. for his assistance in manuscript editing. Thank you to the panel and to J.M.W. for their efforts in the translation of the guidelines into Mandarin Chinese and the making of the pocket book edition for clinical practice.

\section{REFERENCES}

1. Torres J, Mehandru S, Colombel JF, Peyrin-Biroulet L. Crohn's disease. Lancet 2017;389:1741-1755.

2. Loftus EV Jr. Crohn's disease: why the disparity in mortality? Gut 2006;55:447-449.

3. Selinger CP, Leong RW. Mortality from inflammatory bowel diseases. Inflamm Bowel Dis 2012;18:1566-1572.

4. Wei SC, Lin MH, Tung CC, et al. A nationwide populationbased study of the inflammatory bowel diseases between 1998 and 2008 in Taiwan. BMC Gastroenterol 2013;13:166.

5. Molodecky NA, Soon IS, Rabi DM, et al. Increasing incidence and prevalence of the inflammatory bowel diseases with time, based on systematic review. Gastroenterology 2012;142:46-54.
6. Cosnes J, Gower-Rousseau C, Seksik P, Cortot A. Epidemiology and natural history of inflammatory bowel diseases. Gastroenterology 2011;140:1785-1794.

7. Kuo CJ, Yu KH, See LC, et al. The trend of inflammatory bowel diseases in Taiwan: a population-based study. Dig Dis Sci 2015;60:2454-2462.

8. Wang LH, Yang YJ, Cheng WC, Wang WM, Lin SH, Shieh CC. Higher risk for hematological malignancies in inflammatory bowel disease: a nationwide population-based study in Taiwan. Am J Gastroenterol 2016;111:1313-1319.

9. Ng SC, Tang W, Ching JY, et al. Incidence and phenotype of inflammatory bowel disease based on results from the AsiaPacific Crohn's and colitis epidemiology study. Gastroenterology 2013;145:158-165.

10. Gomollón F, Dignass A, Annese V, et al. 3rd European evidence-based consensus on the diagnosis and management of Crohn's disease 2016: part 1: diagnosis and medical management. J Crohns Colitis 2017;11:3-25.

11. Gionchetti P, Dignass A, Danese S, et al. 3rd European evidence-based consensus on the diagnosis and management of Crohn's disease 2016: part 2: surgical management and special situations. J Crohns Colitis 2017;11:135-149.

12. Ooi CJ, Makharia GK, Hilmi I, et al. Asia Pacific consensus statements on Crohn's disease. Part 1: definition, diagnosis, and epidemiology: (Asia Pacific Crohn's Disease Consensus: part 1). J Gastroenterol Hepatol 2016;31:45-55.

13. Ooi CJ, Makharia GK, Hilmi I, et al. Asia-Pacific consensus statements on Crohn's disease. Part 2: management. J Gastroenterol Hepatol 2016;31:56-68.

14. Lichtenstein GR, Hanauer SB, Sandborn WJ; Practice Parameters Committee of American College of Gastroenterology. Management of Crohn's disease in adults. Am J Gastroenterol 2009;104:465-483.

15. Ueno F, Matsui T, Matsumoto T, et al. Evidence-based clinical practice guidelines for Crohn's disease, integrated with formal consensus of experts in Japan. J Gastroenterol 2013;48:31-72.

16. Lan JY. Achieving and sustaining universal health coverage: fiscal reform of the National Health Insurance in Taiwan [published online ahead of print October 25, 2016]. Appl Health Econ Health Policy. doi: 10.1007/s40258-016-0286-6.

17. Shivananda S, Lennard-Jones J, Logan R, et al. Incidence of inflammatory bowel disease across Europe: is there a difference between north and south? Results of the European Collaborative Study on Inflammatory Bowel Disease (EC-IBD). Gut 1996;39:690-697.

18. Ng WK, Wong SH, Ng SC. Changing epidemiological trends of inflammatory bowel disease in Asia. Intest Res 2016;14:111119. 
19. Prideaux L, Kamm MA, De Cruz PP, Chan FK, Ng SC. Inflammatory bowel disease in Asia: a systematic review. J Gastroenterol Hepatol 2012;27:1266-1280.

20. Thia KT, Loftus EV Jr, Sandborn WJ, Yang SK. An update on the epidemiology of inflammatory bowel disease in Asia. Am J Gastroenterol 2008;103:3167-3182.

21. Kim HJ, Hann HJ, Hong SN, et al. Incidence and natural course of inflammatory bowel disease in Korea, 2006-2012: a nationwide population-based study. Inflamm Bowel Dis 2015;21:623630.

22. Asakura K, Nishiwaki Y, Inoue N, Hibi T, Watanabe M, Takebayashi T. Prevalence of ulcerative colitis and Crohn's disease in Japan. J Gastroenterol 2009;44:659-665.

23. Bernstein CN, Wajda A, Svenson LW, et al. The epidemiology of inflammatory bowel disease in Canada: a population-based study. Am J Gastroenterol 2006;101:1559-1568.

24. Talley NJ, Abreu MT, Achkar JP, et al. An evidence-based systematic review on medical therapies for inflammatory bowel disease. Am J Gastroenterol 2011;106 Suppl 1:S2-S25.

25. Gearry RB, Richardson A, Frampton CM, et al. High incidence of Crohn's disease in Canterbury, New Zealand: results of an epidemiologic study. Inflamm Bowel Dis 2006;12:936-943.

26. Economou M, Trikalinos TA, Loizou KT, Tsianos EV, Ioannidis JP. Differential effects of NOD2 variants on Crohn's disease risk and phenotype in diverse populations: a metaanalysis. Am J Gastroenterol 2004;99:2393-2404.

27. Strober W, Asano N, Fuss I, Kitani A, Watanabe T. Cellular and molecular mechanisms underlying NOD2 riskassociated polymorphisms in Crohn's disease. Immunol Rev 2014;260:249-260.

28. Lee GH, Kim CG, Kim JS, Jung HC, Song IS. Frequency analysis of NOD2 gene mutations in Korean patients with Crohn's disease. Korean J Gastroenterol 2005;45:162-168.

29. Hsiao CH, Wei SC, Wong JM, Lai HS, Chang MH, Ni YH. Pediatric Crohn disease: clinical and genetic characteristics in Taiwan. J Pediatr Gastroenterol Nutr 2007;44:342-346.

30. Li M, Gao X, Guo CC, Wu KC, Zhang X, Hu PJ. OCTN and CARD15 gene polymorphism in Chinese patients with inflammatory bowel disease. World J Gastroenterol 2008;14:4923-4927.

31. Yamazaki K, Takazoe M, Tanaka T, Kazumori T, Nakamura Y. Absence of mutation in the NOD2/CARD15 gene among 483 Japanese patients with Crohn's disease. J Hum Genet 2002;47:469-472.

32. Wei SC, Ni YH, Yang HI, et al. A hospital-based study of clinical and genetic features of Crohn's disease. J Formos Med Assoc 2011;110:600-606.
33. Yamazaki K, Onouchi Y, Takazoe M, Kubo M, Nakamura Y, Hata A. Association analysis of genetic variants in IL23R, ATG16L1 and 5p13.1 loci with Crohn's disease in Japanese patients. J Hum Genet 2007;52:575-583.

34. Yang SK, Lee SG, Cho YK, Lim J, Lee I, Song K. Association of TNF-alpha/LTA polymorphisms with Crohn's disease in Koreans. Cytokine 2006;35:13-20.

35. Zipperlen K, Peddle L, Melay B, Hefferton D, Rahman P. Association of TNF-alpha polymorphisms in Crohn disease. Hum Immunol 2005;66:56-59.

36. Imhann F, Vich Vila A, Bonder MJ, et al. Interplay of host genetics and gut microbiota underlying the onset and clinical presentation of inflammatory bowel disease [published online ahead of print October 8, 2016]. Gut. doi: 10.1136/ gutjnl-2016-312135.

37. Fowler EV, Doecke J, Simms LA, et al. ATG16L1 T300A shows strong associations with disease subgroups in a large Australian IBD population: further support for significant disease heterogeneity. Am J Gastroenterol 2008;103:2519-2526.

38. Glas J, Konrad A, Schmechel S, et al. The ATG16L1 gene variants rs2241879 and rs2241880 (T300A) are strongly associated with susceptibility to Crohn's disease in the German population. Am J Gastroenterol 2008;103:682-691.

39. Latiano A, Palmieri O, Valvano MR, et al. Replication of interleukin 23 receptor and autophagy-related 16-like 1 association in adult- and pediatric-onset inflammatory bowel disease in Italy. World J Gastroenterol 2008;14:4643-4651.

40. Newman WG, Zhang Q, Liu X, Amos CI, Siminovitch KA. Genetic variants in IL-23R and ATG16L1 independently predispose to increased susceptibility to Crohn's disease in a Canadian population. J Clin Gastroenterol 2009;43:444-447.

41. Roberts RL, Gearry RB, Hollis-Moffatt JE, et al. IL23R R381Q and ATG16L1 T300A are strongly associated with Crohn's disease in a study of New Zealand Caucasians with inflammatory bowel disease. Am J Gastroenterol 2007;102:2754-2761.

42. Yang SK, Park M, Lim J, et al. Contribution of IL23R but not ATG16L1 to Crohn's disease susceptibility in Koreans. Inflamm Bowel Dis 2009;15:1385-1390.

43. Zhi J, Zhi FC, Chen ZY, et al. Correlation of the autophagosome gene ATG16L1 polymorphism and inflammatory bowel disease. Nan Fang Yi Ke Da Xue Xue Bao 2008;28:649-651.

44. Tedesco FJ, Hardin RD, Harper RN, Edwards BH. Infectious colitis endoscopically simulating inflammatory bowel disease: a prospective evaluation. Gastrointest Endosc 1983;29:195197.

45. De Hertogh G, Geboes K. Crohn's disease and infections: a complex relationship. MedGenMed 2004;6:14. 
46. Pimentel M, Chang M, Chow EJ, et al. Identification of a prodromal period in Crohn's disease but not ulcerative colitis. Am J Gastroenterol 2000;95:3458-3462.

47. Fine KD, Schiller LR. AGA technical review on the evaluation and management of chronic diarrhea. Gastroenterology 1999;116:1464-1486.

48. Mahid SS, Minor KS, Soto RE, Hornung CA, Galandiuk S. Smoking and inflammatory bowel disease: a meta-analysis. Mayo Clin Proc 2006;81:1462-1471.

49. Moller FT, Andersen V, Wohlfahrt J, Jess T. Familial risk of inflammatory bowel disease: a population-based cohort study 1977-2011. Am J Gastroenterol 2015;110:564-571.

50. Eglinton TW, Barclay ML, Gearry RB, Frizelle FA. The spectrum of perianal Crohn's disease in a population-based cohort. Dis Colon Rectum 2012;55:773-777.

51. Best WR, Becktel JM, Singleton JW, Kern F Jr. Development of a Crohn's disease activity index. National Cooperative Crohn's Disease Study. Gastroenterology 1976;70:439-444.

52. Schroeder KW, Tremaine WJ, Ilstrup DM. Coated oral 5-aminosalicylic acid therapy for mildly to moderately active ulcerative colitis: a randomized study. N Engl J Med 1987;317:16251629.

53. Hyams JS, Ferry GD, Mandel FS, et al. Development and validation of a pediatric Crohn's disease activity index. J Pediatr Gastroenterol Nutr 1991;12:439-447.

54. Magro F, Langner C, Driessen A, et al. European consensus on the histopathology of inflammatory bowel disease. J Crohns Colitis 2013;7:827-851.

55. Makkar R, Bo S. Colonoscopic perforation in inflammatory bowel disease. Gastroenterol Hepatol (N Y) 2013;9:573-583.

56. Fausel RA, Kornbluth A, Dubinsky MC. The first endoscopy in suspected inflammatory bowel disease. Gastrointest Endosc Clin N Am 2016;26:593-610.

57. Lee JM, Lee KM. Endoscopic diagnosis and differentiation of inflammatory bowel disease. Clin Endosc 2016;49:370-375.

58. Mary JY, Modigliani R. Development and validation of an endoscopic index of the severity for Crohn's disease: a prospective multicentre study. Groupe d'Etudes Thérapeutiques des Affections Inflammatoires du Tube Digestif (GETAID). Gut 1989;30:983-989.

59. Daperno M, D’Haens G, Van Assche G, et al. Development and validation of a new, simplified endoscopic activity score for Crohn's disease: the SES-CD. Gastrointest Endosc 2004;60:505512.

60. D'Incà R, Caccaro R. Measuring disease activity in Crohn's disease: what is currently available to the clinician. Clin Exp Gastroenterol 2014;7:151-161.
61. Weng MT, Wei SC, Lin CC, et al. Seminar report from the 2014 Taiwan Society of Inflammatory Bowel Disease (TSIBD) spring forum (May 24th, 2014): Crohn's disease versus intestinal tuberculosis infection. Intest Res 2015;13:6-10.

62. Keane J, Gershon S, Wise RP, et al. Tuberculosis associated with infliximab, a tumor necrosis factor alpha-neutralizing agent. N Engl J Med 2001;345:1098-1104.

63. Pratap Mouli V, Munot K, Ananthakrishnan A, et al. Endoscopic and clinical responses to anti-tubercular therapy can differentiate intestinal tuberculosis from Crohn's disease. Aliment Pharmacol Ther 2017;45:27-36.

64. Sakuraba A, Iwao Y, Matsuoka K, et al. Endoscopic and pathologic changes of the upper gastrointestinal tract in Crohn's disease. Biomed Res Int 2014;2014:610767.

65. Annunziata ML, Caviglia R, Papparella LG, Cicala M. Upper gastrointestinal involvement of Crohn's disease: a prospective study on the role of upper endoscopy in the diagnostic workup. Dig Dis Sci 2012;57:1618-1623.

66. Freeman HJ. Application of the Montreal classification for Crohn's disease to a single clinician database of 1015 patients. Can J Gastroenterol 2007;21:363-366.

67. Witte AM, Veenendaal RA, Van Hogezand RA, Verspaget HW, Lamers CB. Crohn's disease of the upper gastrointestinal tract: the value of endoscopic examination. Scand J Gastroenterol Suppl 1998;225:100-105.

68. de Melo SW Jr, Di Palma JA. The role of capsule endoscopy in evaluating inflammatory bowel disease. Gastroenterol Clin North Am 2012;41:315-323.

69. Dionisio PM, Gurudu SR, Leighton JA, et al. Capsule endoscopy has a significantly higher diagnostic yield in patients with suspected and established small-bowel Crohn's disease: a meta-analysis. Am J Gastroenterol 2010;105:1240-1248.

70. Triester SL, Leighton JA, Leontiadis GI, et al. A meta-analysis of the yield of capsule endoscopy compared to other diagnostic modalities in patients with non-stricturing small bowel Crohn's disease. Am J Gastroenterol 2006;101:954-964.

71. Leighton JA, Legnani P, Seidman EG. Role of capsule endoscopy in inflammatory bowel disease: where we are and where we are going. Inflamm Bowel Dis 2007;13:331-337.

72. Kopylov U, Carter D, Eliakim AR. Capsule endoscopy and deep enteroscopy in irritable bowel disease. Gastrointest Endosc Clin N Am 2016;26:611-627.

73. Pennazio M, Spada C, Eliakim R, et al. Small-bowel capsule endoscopy and device-assisted enteroscopy for diagnosis and treatment of small-bowel disorders: European Society of Gastrointestinal Endoscopy (ESGE) clinical guideline. Endoscopy 2015;47:352-376. 
74. Panes J, Bouhnik Y, Reinisch W, et al. Imaging techniques for assessment of inflammatory bowel disease: joint ECCO and ESGAR evidence-based consensus guidelines. J Crohns Colitis 2013;7:556-585.

75. Feuerbach S. MRI enterography: the future of small bowel diagnostics? Dig Dis 2010;28:433-438.

76. Migaleddu V, Scanu AM, Quaia E, et al. Contrast-enhanced ultrasonographic evaluation of inflammatory activity in Crohn's disease. Gastroenterology 2009;137:43-52.

77. Hafeez R, Greenhalgh R, Rajan J, et al. Use of small bowel imaging for the diagnosis and staging of Crohn's disease: a survey of current UK practice. Br J Radiol 2011;84:508-517.

78. Lee SS, Kim AY, Yang SK, et al. Crohn disease of the small bowel: comparison of CT enterography, MR enterography, and small-bowel follow-through as diagnostic techniques. Radiology 2009;251:751-761.

79. Ho IK, Cash BD, Cohen H, et al. Radiation exposure in gastroenterology: improving patient and staff protection. Am J Gastroenterol 2014;109:1180-1194.

80. Peloquin JM, Pardi DS, Sandborn WJ, et al. Diagnostic ionizing radiation exposure in a population-based cohort of patients with inflammatory bowel disease. Am J Gastroenterol 2008;103:2015-2022.

81. Jaffe TA, Gaca AM, Delaney S, et al. Radiation doses from small-bowel follow-through and abdominopelvic MDCT in Crohn's disease. AJR Am J Roentgenol 2007;189:1015-1022.

82. Bressenot A, Geboes K, Vignaud JM, Guéant JL, Peyrin-Biroulet L. Microscopic features for initial diagnosis and disease activity evaluation in inflammatory bowel disease. Inflamm Bowel Dis 2013;19:1745-1752.

83. Jenkins D, Balsitis M, Gallivan S, et al. Guidelines for the initial biopsy diagnosis of suspected chronic idiopathic inflammatory bowel disease: the British Society of Gastroenterology Initiative. J Clin Pathol 1997;50:93-105.

84. Walsh AJ, Bryant RV, Travis SP. Current best practice for disease activity assessment in IBD. Nat Rev Gastroenterol Hepatol 2016;13:567-579.

85. Ott JJ, Stevens GA, Groeger J, Wiersma ST. Global epidemiology of hepatitis B virus infection: new estimates of age-specific HBsAg seroprevalence and endemicity. Vaccine 2012;30:22122219.

86. Rahier JF, Magro F, Abreu C, et al. Second European evidencebased consensus on the prevention, diagnosis and management of opportunistic infections in inflammatory bowel disease. J Crohns Colitis 2014;8:443-468.

87. Cheon JH. Understanding the complications of anti-tumor necrosis factor therapy in East Asian patients with inflammatory bowel disease. J Gastroenterol Hepatol 2017;32:769-777.
88. Loras C, Gisbert JP, Mínguez M, et al. Liver dysfunction related to hepatitis $\mathrm{B}$ and $\mathrm{C}$ in patients with inflammatory bowel disease treated with immunosuppressive therapy. Gut 2010;59:1340-1346.

89. Park SH, Yang SK, Lim YS, et al. Clinical courses of chronic hepatitis B virus infection and inflammatory bowel disease in patients with both diseases. Inflamm Bowel Dis 2012;18:20042010.

90. Horsburgh CR Jr, Rubin EJ. Clinical practice: latent tuberculosis infection in the United States. N Engl J Med 2011;364:14411448.

91. Tuberculosis diagnosis and treatment guidelines (version 5.1). Centers for Disease Control, R.O.C. (Taiwan) Web site http:// www.cdc.gov.tw/professional/info.aspx?treeid=beac9c103 df952c4\&nowtreeid=6744c19c09435458\&tid=B02B73C3D 6F15437. Updated December 17, 2015. Accessed March 3, 2017.

92. Summers RW, Switz DM, Sessions JT Jr, et al. National Cooperative Crohn's Disease Study: results of drug treatment. Gastroenterology 1979;77:847-869.

93. Malchow H, Ewe K, Brandes JW, et al. European cooperative Crohn's disease study (ECCDS): results of drug treatment. Gastroenterology 1984;86:249-266.

94. Tremaine WJ, Schroeder KW, Harrison JM, Zinsmeister AR. A randomized, double-blind, placebo-controlled trial of the oral mesalamine (5-ASA) preparation, Asacol, in the treatment of symptomatic Crohn's colitis and ileocolitis. J Clin Gastroenterol 1994;19:278-282.

95. Singleton JW, Hanauer SB, Gitnick GL, et al. Mesalamine capsules for the treatment of active Crohn's disease: results of a 16-week trial. Pentasa Crohn's Disease Study Group. Gastroenterology 1993;104:1293-1301.

96. Lim WC, Wang Y, MacDonald JK, Hanauer S. Aminosalicylates for induction of remission or response in Crohn's disease. Cochrane Database Syst Rev 2016;7:CD008870. doi: 10.1002/14651858.CD008870.pub2.

97. Hanauer SB, Strömberg U. Oral Pentasa in the treatment of active Crohn's disease: a meta-analysis of double-blind, placebocontrolled trials. Clin Gastroenterol Hepatol 2004;2:379-388.

98. Martin F, Sutherland L, Beck IT, et al. Oral 5-ASA versus prednisolone in short term treatment of Crohn's disease: a multicentre controlled trial. Can J Gastroenterol 1990;4:452-457.

99. Gross V, Andus T, Fischbach W, et al. Comparison between high dose 5-aminosalicylic acid and 6-methylprednisolone in active Crohn's ileocolitis: a multicenter randomized doubleblind study. German 5-ASA Study Group. Z Gastroenterol 1995;33:581-584. 
100. Prantera C, Cottone M, Pallone F, et al. Mesalamine in the treatment of mild to moderate active Crohn's ileitis: results of a randomized, multicenter trial. Gastroenterology 1999;116:521-526.

101. Thomsen OO, Cortot A, Jewell D, et al. A comparison of budesonide and mesalamine for active Crohn's disease. International Budesonide-Mesalamine Study Group. N Engl J Med 1998;339:370-374.

102. Rezaie A, Kuenzig ME, Benchimol EI, et al. Budesonide for induction of remission in Crohn's disease. Cochrane Database Syst Rev 2015:(6);CD000296. doi: 10.1002/14651858. CD000296.pub4.

103. Benchimol EI, Seow CH, Steinhart AH, Griffiths AM. Traditional corticosteroids for induction of remission in Crohn's disease. Cochrane Database Syst Rev 2008:(2);CD006792. doi: 10.1002/14651858.CD006792.pub2.

104. Steinhart AH, Ewe K, Griffiths AM, Modigliani R, Thomsen OO. Corticosteroids for maintenance of remission in Crohn's disease. Cochrane Database Syst Rev 2003:(4);CD000301. doi: 10.1002/14651858.CD000301.

105. McDonald JW, Wang Y, Tsoulis DJ, MacDonald JK, Feagan BG. Methotrexate for induction of remission in refractory Crohn's disease. Cochrane Database Syst Rev 2014:(8);CD003459. doi: 10.1002/14651858.CD003459.pub4.

106. Feagan BG, Rochon J, Fedorak RN, et al. Methotrexate for the treatment of Crohn's disease. The North American Crohn's Study Group Investigators. N Engl J Med 1995;332:292-297.

107. Targan SR, Hanauer SB, van Deventer SJ, et al. A short-term study of chimeric monoclonal antibody cA2 to tumor necrosis factor alpha for Crohn's disease. Crohn's Disease cA2 Study Group. N Engl J Med 1997;337:1029-1035.

108. Schnitzler F, Fidder H, Ferrante M, et al. Long-term outcome of treatment with infliximab in 614 patients with Crohn's disease: results from a single-centre cohort. Gut 2009;58:492-500.

109. Hanauer SB, Sandborn WJ, Rutgeerts P, et al. Human antitumor necrosis factor monoclonal antibody (adalimumab) in Crohn's disease: the CLASSIC-I trial. Gastroenterology 2006;130:323-333.

110. Schreiber S, Rutgeerts P, Fedorak RN, et al. A randomized, placebo-controlled trial of certolizumab pegol (CDP870) for treatment of Crohn's disease. Gastroenterology 2005;129:807818.

111. Sandborn WJ, Feagan BG, Stoinov S, et al. Certolizumab pegol for the treatment of Crohn's disease. N Engl J Med 2007;357:228-238.

112. Sandborn WJ, Rutgeerts P, Enns R, et al. Adalimumab induction therapy for Crohn disease previously treated with infliximab: a randomized trial. Ann Intern Med 2007;146:829-838.
113. Sandborn WJ, Feagan BG, Rutgeerts P, et al. Vedolizumab as induction and maintenance therapy for Crohn's disease. N Engl J Med 2013;369:711-721

114. Sands BE, Feagan BG, Rutgeerts P, et al. Effects of vedolizumab induction therapy for patients with Crohn's disease in whom tumor necrosis factor antagonist treatment failed. Gastroenterology 2014;147:618-627.

115. Sands BE, Sandborn WJ, Van Assche G, et al. Vedolizumab as induction and maintenance therapy for Crohn's disease in patients naïve to or who have failed tumor necrosis factor antagonist therapy. Inflamm Bowel Dis 2017;23:97-106.

116. Feagan BG, Sandborn WJ, Gasink C, et al. Ustekinumab as induction and maintenance therapy for Crohn's disease. N Engl J Med 2016;375:1946-1960.

117. Chande N, Patton PH, Tsoulis DJ, Thomas BS, MacDonald JK. Azathioprine or 6-mercaptopurine for maintenance of remission in Crohn's disease. Cochrane Database Syst Rev 2015:(10);CD000067. doi: 10.1002/14651858.CD000067.pub3.

118. Patel V, Wang Y, MacDonald JK, McDonald JW, Chande N. Methotrexate for maintenance of remission in Crohn's disease. Cochrane Database Syst Rev 2014:(8);CD006884. doi: 10.1002/14651858.CD006884.pub3.

119. Peyrin-Biroulet L, Deltenre P, de Suray N, et al. Efficacy and safety of tumor necrosis factor antagonists in Crohn's disease: meta-analysis of placebo-controlled trials. Clin Gastroenterol Hepatol 2008;6:644-653.

120. Behm BW, Bickston SJ. Tumor necrosis factor-alpha antibody for maintenance of remission in Crohn's disease. Cochrane Database Syst Rev 2008:(1);CD006893. doi: 10.1002/14651858. CD006893.

121. Van Assche G, Magdelaine-Beuzelin C, D'Haens G, et al. Withdrawal of immunosuppression in Crohn's disease treated with scheduled infliximab maintenance: a randomized trial. Gastroenterology 2008;134:1861-1868.

122. Matsumoto T, Motoya S, Watanabe K, et al. Adalimumab monotherapy and a combination with azathioprine for Crohn's disease: a prospective, randomized trial. J Crohns Colitis 2016;10:1259-1266.

123. Colombel JF, Sandborn WJ, Reinisch W, et al. Infliximab, azathioprine, or combination therapy for Crohn's disease. N Engl J Med 2010;362:1383-1395.

124. Kruis W, Nguyen PG, Morgenstern J. Promises and dangers of combination therapy. Dig Dis 2017;35:56-60.

125. Dignass A, Van Assche G, Lindsay JO, et al. The second European evidence-based consensus on the diagnosis and management of Crohn's disease: current management. J Crohns Colitis 2010;4:28-62. 
126. Aratari A, Papi C, Leandro G, Viscido A, Capurso L, Caprilli R. Early versus late surgery for ileo-caecal Crohn's disease. Aliment Pharmacol Ther 2007;26:1303-1312.

127. Annese V, Daperno M, Rutter MD, et al. European evidence based consensus for endoscopy in inflammatory bowel disease. J Crohns Colitis 2013;7:982-1018.

128. Baert F, Moortgat L, Van Assche G, et al. Mucosal healing predicts sustained clinical remission in patients with early-stage Crohn's disease. Gastroenterology 2010;138:463-468.

129. Hébuterne X, Lémann M, Bouhnik Y, et al. Endoscopic improvement of mucosal lesions in patients with moderate to severe ileocolonic Crohn's disease following treatment with certolizumab pegol. Gut 2013;62:201-208.

130. Peyrin-Biroulet L, Reinisch W, Colombel JF, et al. Clinical disease activity, C-reactive protein normalisation and mucosal healing in Crohn's disease in the SONIC trial. Gut 2014;63:8895.

131. Rutgeerts P, Geboes K, Vantrappen G, Kerremans R, Coenegrachts JL, Coremans G. Natural history of recurrent Crohn's disease at the ileocolonic anastomosis after curative surgery. Gut 1984;25:665-672.

132. Olaison G, Smedh K, Sjödahl R. Natural course of Crohn's disease after ileocolic resection: endoscopically visualised ileal ulcers preceding symptoms. Gut 1992;33:331-335.

133. Tytgat GN, Mulder CJ, Brummelkamp WH. Endoscopic lesions in Crohn's disease early after ileocecal resection. Endoscopy 1988;20:260-262.

134. Rutgeerts P, Geboes K, Vantrappen G, Beyls J, Kerremans R, Hiele M. Predictability of the postoperative course of Crohn's disease. Gastroenterology 1990;99:956-963.

135. Leighton JA, Shen B, Baron TH, et al. ASGE guideline: endoscopy in the diagnosis and treatment of inflammatory bowel disease. Gastrointest Endosc 2006;63:558-565.

136. Fagan EA, Dyck RF, Maton PN, et al. Serum levels of C-reactive protein in Crohn's disease and ulcerative colitis. Eur J Clin Invest 1982;12:351-359.

137. Yang DH, Yang SK, Park SH, et al. Usefulness of C-reactive protein as a disease activity marker in Crohn's disease according to the location of disease. Gut Liver 2015;9:80-86.

138. Kiss LS, Papp M, Lovasz BD, et al. High-sensitivity C-reactive protein for identification of disease phenotype, active disease, and clinical relapses in Crohn's disease: a marker for patient classification? Inflamm Bowel Dis 2012;18:1647-1654.

139. Bjarnason I, Sherwood R. Fecal calprotectin: a significant step in the noninvasive assessment of intestinal inflammation. J Pediatr Gastroenterol Nutr 2001;33:11-13.
140. Summerton CB, Longlands MG, Wiener K, Shreeve DR. Faecal calprotectin: a marker of inflammation throughout the intestinal tract. Eur J Gastroenterol Hepatol 2002;14:841-845.

141. Tibble JA, Sigthorsson G, Foster R, Forgacs I, Bjarnason I. Use of surrogate markers of inflammation and Rome criteria to distinguish organic from nonorganic intestinal disease. Gastroenterology 2002;123:450-460.

142. Tibble J, Teahon K, Thjodleifsson B, et al. A simple method for assessing intestinal inflammation in Crohn's disease. Gut 2000;47:506-513.

143. Lin WC, Wong JM, Tung CC, et al. Fecal calprotectin correlated with endoscopic remission for Asian inflammatory bowel disease patients. World J Gastroenterol 2015;21:13566-13573.

144. Solem CA, Loftus EV Jr, Tremaine WJ, Harmsen WS, Zinsmeister AR, Sandborn WJ. Correlation of C-reactive protein with clinical, endoscopic, histologic, and radiographic activity in inflammatory bowel disease. Inflamm Bowel Dis 2005;11:707712 .

145. Vermeire S, Van Assche G, Rutgeerts P. C-reactive protein as a marker for inflammatory bowel disease. Inflamm Bowel Dis 2004;10:661-665.

146. Jürgens M, Mahachie John JM, Cleynen I, et al. Levels of Creactive protein are associated with response to infliximab therapy in patients with Crohn's disease. Clin Gastroenterol Hepatol 2011;9:421-427.

147. Tibble JA, Sigthorsson G, Bridger S, Fagerhol MK, Bjarnason I. Surrogate markers of intestinal inflammation are predictive of relapse in patients with inflammatory bowel disease. Gastroenterology 2000;119:15-22.

148. Ferreiro-Iglesias R, Barreiro-de Acosta M, Lorenzo-Gonzalez A, Dominguez-Muñoz JE. Accuracy of consecutive fecal calprotectin measurements to predict relapse in inflammatory bowel disease patients under maintenance with anti-tnf therapy: a prospective longitudinal cohort study [published online ahead of print December 14, 2016]. J Clin Gastroenterol. doi: 10.1097/MCG.0000000000000774.

149. Sipponen T, Savilahti E, Kolho KL, Nuutinen H, Turunen U, Färkkilä M. Crohn's disease activity assessed by fecal calprotectin and lactoferrin: correlation with Crohn's disease activity index and endoscopic findings. Inflamm Bowel Dis 2008;14:40-46.

150. Moreno N, Ripollés T, Paredes JM, et al. Usefulness of abdominal ultrasonography in the analysis of endoscopic activity in patients with Crohn's disease: changes following treatment with immunomodulators and/or anti-TNF antibodies. J Crohns Colitis 2014;8:1079-1087. 
151. Paredes JM, Ripollés T, Cortés X, et al. Abdominal sonographic changes after antibody to tumor necrosis factor (anti-TNF) alpha therapy in Crohn's Disease. Dig Dis Sci 2010;55:404-410.

152. Deepak P, Fletcher JG, Fidler JL, Bruining DH. Computed tomography and magnetic resonance enterography in Crohn's disease: assessment of radiologic criteria and endpoints for clinical practice and trials. Inflamm Bowel Dis 2016;22:22802288.

153. Rimola J, Rodriguez S, García-Bosch O, et al. Magnetic resonance for assessment of disease activity and severity in ileocolonic Crohn's disease. Gut 2009;58:1113-1120.

154. Steward MJ, Punwani S, Proctor I, et al. Non-perforating small bowel Crohn's disease assessed by MRI enterography: derivation and histopathological validation of an MR-based activity index. Eur J Radiol 2012;81:2080-2088.

155. Makanyanga JC, Pendsé D, Dikaios N, et al. Evaluation of Crohn's disease activity: initial validation of a magnetic resonance enterography global score (MEGS) against faecal calprotectin. Eur Radiol 2014;24:277-287.

156. Oussalah A, Laurent V, Bruot O, et al. Diffusion-weighted magnetic resonance without bowel preparation for detecting colonic inflammation in inflammatory bowel disease. Gut 2010;59:1056-1065.

157. Baars JE, Nuij VJ, Oldenburg B, Kuipers EJ, van der Woude CJ. Majority of patients with inflammatory bowel disease in clinical remission have mucosal inflammation. Inflamm Bowel Dis 2012;18:1634-1640.

158. Kim NK, Senagore AJ, Luchtefeld MA, et al. Long-term outcome after ileocecal resection for Crohn's disease. Am Surg 1997;63:627-633.

159. Weston LA, Roberts PL, Schoetz DJ Jr, Coller JA, Murray JJ, Rusin LC. Ileocolic resection for acute presentation of Crohn's disease of the ileum. Dis Colon Rectum 1996;39:841-846.

160. Bass JA, Goldman J, Jackson MA, et al. Pediatric Crohn disease presenting as appendicitis: differentiating features from typical appendicitis. Eur J Pediatr Surg 2012;22:274-278.

161. Hsu WF, Wu CS, Wu JM, Chung CS. Ileal Crohn's disease with perforation misdiagnosed as ruptured appendicitis: a case report. J Formos Med Assoc 2013;112:652-653.

162. Han H, Kim H, Rehman A, Jang SM, Paik SS. Appendiceal Crohn's disease clinically presenting as acute appendicitis. World J Clin Cases 2014;2:888-892.

163. Chachu KA, Osterman MT. How to diagnose and treat IBD mimics in the refractory IBD patient who does not have IBD. Inflamm Bowel Dis 2016;22:1262-1274.
164. Goldstein NS, Leon-Armin C, Mani A. Crohn's colitis-like changes in sigmoid diverticulitis specimens is usually an idiosyncratic inflammatory response to the diverticulosis rather than Crohn's colitis. Am J Surg Pathol 2000;24:668-675.

165. Mukherjee K, Rinker EB, Kressin MK, Tarpley JL, Muldoon RL. Small bowel diverticulitis masquerading as Crohn's disease. Am Surg 2013;79:E246-E248.

166. Garcia JC, Persky SE, Bonis PA, Topazian M. Abscesses in Crohn's disease: outcome of medical versus surgical treatment. J Clin Gastroenterol 2001;32:409-412.

167. Gervais DA, Hahn PF, O'Neill MJ, Mueller PR. Percutaneous abscess drainage in Crohn disease: technical success and short- and long-term outcomes during 14 years. Radiology 2002;222:645-651.

168. Feagins LA, Holubar SD, Kane SV, Spechler SJ. Current strategies in the management of intra-abdominal abscesses in Crohn's disease. Clin Gastroenterol Hepatol 2011;9:842-850.

169. Müller-Wille R, Iesalnieks I, Dornia C, et al. Influence of percutaneous abscess drainage on severe postoperative septic complications in patients with Crohn's disease. Int J Colorectal Dis 2011;26:769-774.

170. Zerbib P, Koriche D, Truant S, et al. Pre-operative management is associated with low rate of post-operative morbidity in penetrating Crohn's disease. Aliment Pharmacol Ther 2010;32:459465.

171. Shen B, Patel S, Lian L. Natural history of Crohn's disease in patients who underwent intentional restorative proctocolectomy with ileal pouch-anal anastomosis. Aliment Pharmacol Ther 2010;31:745-753.

172. Reese GE, Lovegrove RE, Tilney HS, et al. The effect of Crohn's disease on outcomes after restorative proctocolectomy. Dis Colon Rectum 2007;50:239-250.

173. Aberra FN, Lewis JD, Hass D, Rombeau JL, Osborne B, Lichtenstein GR. Corticosteroids and immunomodulators: postoperative infectious complication risk in inflammatory bowel disease patients. Gastroenterology 2003;125:320-327.

174. Tzivanakis A, Singh JC, Guy RJ, Travis SP, Mortensen NJ, George BD. Influence of risk factors on the safety of ileocolic anastomosis in Crohn's disease surgery. Dis Colon Rectum 2012;55:558-562.

175. Yamamoto T, Allan RN, Keighley MR. Risk factors for intraabdominal sepsis after surgery in Crohn's disease. Dis Colon Rectum 2000;43:1141-1145.

176. Peyrin-Biroulet L, Harmsen WS, Tremaine WJ, Zinsmeister AR, Sandborn WJ, Loftus EV Jr. Surgery in a population-based cohort of Crohn's disease from Olmsted County, Minnesota (1970-2004). Am J Gastroenterol 2012;107:1693-1701. 
177. Reese GE, Nanidis T, Borysiewicz C, Yamamoto T, Orchard T, Tekkis PP. The effect of smoking after surgery for Crohn's disease: a meta-analysis of observational studies. Int J Colorectal Dis 2008;23:1213-1221.

178. Van Assche G, Dignass A, Reinisch W, et al. The second European evidence-based consensus on the diagnosis and management of Crohn's disease: special situations. J Crohns Colitis 2010;4:63-101.

179. Caprilli R, Taddei G, Viscido A. In favour of prophylactic treatment for post-operative recurrence in Crohn's disease. Ital J Gastroenterol Hepatol 1998;30:219-225.

180. McLeod RS, Wolff BG, Steinhart AH, et al. Prophylactic mesalamine treatment decreases postoperative recurrence of Crohn's disease. Gastroenterology 1995;109:404-413.

181. Carla-Moreau A, Paul S, Roblin X, Genin C, Peyrin-Biroulet L. Prevention and treatment of postoperative Crohn's disease recurrence with anti-TNF therapy: a meta-analysis of controlled trials. Dig Liver Dis 2015;47:191-196.

182. Coelho J, Beaugerie L, Colombel JF, et al. Pregnancy outcome in patients with inflammatory bowel disease treated with thiopurines: cohort from the CESAME study. Gut 2011;60:198-203.

183. Alstead EM, Ritchie JK, Lennard-Jones JE, Farthing MJ, Clark ML. Safety of azathioprine in pregnancy in inflammatory bowel disease. Gastroenterology 1990;99:443-446.

184. Francella A, Dyan A, Bodian C, Rubin P, Chapman M, Present DH. The safety of 6-mercaptopurine for childbearing patients with inflammatory bowel disease: a retrospective cohort study. Gastroenterology 2003;124:9-17.

185. Nørgård B, Pedersen L, Fonager K, Rasmussen SN, Sørensen HT. Azathioprine, mercaptopurine and birth outcome: a population-based cohort study. Aliment Pharmacol Ther 2003;17:827-834.

186. Mahadevan U, Kane S, Sandborn WJ, et al. Intentional infliximab use during pregnancy for induction or maintenance of remission in Crohn's disease. Aliment Pharmacol Ther 2005;21:733-738.

187. Katz JA, Antoni C, Keenan GF, Smith DE, Jacobs SJ, Lichtenstein GR. Outcome of pregnancy in women receiving infliximab for the treatment of Crohn's disease and rheumatoid arthritis. Am J Gastroenterol 2004;99:2385-2392.

188. Vesga L, Terdiman JP, Mahadevan U. Adalimumab use in pregnancy. Gut 2005;54:890.

189. Mishkin DS, Van Deinse W, Becker JM, Farraye FA. Successful use of adalimumab (Humira) for Crohn's disease in pregnancy. Inflamm Bowel Dis 2006;12:827-828.

190. Coburn LA, Wise PE, Schwartz DA. The successful use of adalimumab to treat active Crohn's disease of an ileoanal pouch during pregnancy. Dig Dis Sci 2006;51:2045-2047.
191. Rahimi R, Nikfar S, Rezaie A, Abdollahi M. Pregnancy outcome in women with inflammatory bowel disease following exposure to 5-aminosalicylic acid drugs: a meta-analysis. Reprod Toxicol 2008;25:271-275.

192. Silverman DA, Ford J, Shaw I, Probert CS. Is mesalazine really safe for use in breastfeeding mothers? Gut 2005;54:170-171.

193. Ost L, Wettrell G, Björkhem I, Rane A. Prednisolone excretion in human milk. J Pediatr 1985;106:1008-1011.

194. Gardiner SJ, Gearry RB, Roberts RL, Zhang M, Barclay ML, Begg EJ. Exposure to thiopurine drugs through breast milk is low based on metabolite concentrations in mother-infant pairs. Br J Clin Pharmacol 2006;62:453-456.

195. Mottet C, Juillerat P, Pittet V, et al. Pregnancy and breastfeeding in patients with Crohn's disease. Digestion 2007;76:149-160.

196. Barclay AR, Russell RK, Wilson ML, Gilmour WH, Satsangi J, Wilson DC. Systematic review: the role of breastfeeding in the development of pediatric inflammatory bowel disease. J Pediatr 2009;155:421-426.

197. Ruemmele FM, Veres G, Kolho KL, et al. Consensus guidelines of ECCO/ESPGHAN on the medical management of pediatric Crohn's disease. J Crohns Colitis 2014;8:1179-1207.

198. Byron MA, Jackson J, Ansell BM. Effect of different corticosteroid regimens on hypothalamic-pituitary-adrenal axis and growth in juvenile chronic arthritis. J R Soc Med 1983;76:452-457.

199. Markowitz J, Grancher K, Kohn N, Lesser M, Daum F. A multicenter trial of 6-mercaptopurine and prednisone in children with newly diagnosed Crohn's disease. Gastroenterology 2000;119:895-902.

200. Jaspers GJ, Verkade HJ, Escher JC, de Ridder L, Taminiau JA, Rings EH. Azathioprine maintains first remission in newly diagnosed pediatric Crohn's disease. Inflamm Bowel Dis 2006;12:831-836.

201. Fuentes D, Torrente F, Keady S, et al. High-dose azathioprine in children with inflammatory bowel disease. Aliment Pharmacol Ther 2003;17:913-921.

202. Turner D, Grossman AB, Rosh J, et al. Methotrexate following unsuccessful thiopurine therapy in pediatric Crohn's disease. Am J Gastroenterol 2007;102:2804-2812.

203. Hyams J, Crandall W, Kugathasan S, et al. Induction and maintenance infliximab therapy for the treatment of moderateto-severe Crohn's disease in children. Gastroenterology 2007;132:863-873.

204. Ruemmele FM, Lachaux A, Cézard JP, et al. Efficacy of infliximab in pediatric Crohn's disease: a randomized multicenter open-label trial comparing scheduled to on demand maintenance therapy. Inflamm Bowel Dis 2009;15:388-394. 
205. Hyams JS, Griffiths A, Markowitz J, et al. Safety and efficacy of adalimumab for moderate to severe Crohn's disease in children. Gastroenterology 2012;143:365-374.

206. Hyams JS, Lerer T, Griffiths A, et al. Long-term outcome of maintenance infliximab therapy in children with Crohn's disease. Inflamm Bowel Dis 2009;15:816-822.

207. Smith R, Hicks D, Tomljanovich PI, Lele SB, Rajput A, Dunn KB. Adenocarcinoma arising from chronic perianal Crohn's disease: case report and review of the literature. Am Surg 2008;74:59-61.

208. Shwaartz C, Munger JA, Deliz JR, et al. Fistula-associated anorectal cancer in the setting of Crohn's disease. Dis Colon Rectum 2016;59:1168-1173.

209. Laukoetter MG, Mennigen R, Hannig CM, et al. Intestinal cancer risk in Crohn's disease: a meta-analysis. J Gastrointest Surg 2011;15:576-583.

210. Winkler R, Wittmer A, Heusermann U. Cancer and Crohn's disease. Z Gastroenterol 2002;40:569-576.

211. Thomas M, Bienkowski R, Vandermeer TJ, Trostle D, Cagir B. Malignant transformation in perianal fistulas of Crohn's disease: a systematic review of literature. J Gastrointest Surg 2010;14:66-73.

212. Annese V, Beaugerie L, Egan L, et al. European evidence-based consensus: inflammatory bowel disease and malignancies. J Crohns Colitis 2015;9:945-965.

213. Elriz K, Carrat F, Carbonnel F, et al. Incidence, presentation, and prognosis of small bowel adenocarcinoma in patients with small bowel Crohn's disease: a prospective observational study. Inflamm Bowel Dis 2013;19:1823-1826.

214. Biancone L, Zuzzi S, Ranieri M, et al. Fistulizing pattern in Crohn's disease and pancolitis in ulcerative colitis are independent risk factors for cancer: a single-center cohort study. J Crohns Colitis 2012;6:578-587.

215. Jess T, Horváth-Puhó E, Fallingborg J, Rasmussen HH, Jacobsen BA. Cancer risk in inflammatory bowel disease according to patient phenotype and treatment: a Danish populationbased cohort study. Am J Gastroenterol 2013;108:1869-1876.

216. Long MD, Herfarth HH, Pipkin CA, Porter CQ, Sandler RS, Kappelman MD. Increased risk for non-melanoma skin cancer in patients with inflammatory bowel disease. Clin Gastroenterol Hepatol 2010;8:268-274.

217. Singh H, Nugent Z, Demers AA, Bernstein CN. Increased risk of nonmelanoma skin cancers among individuals with inflammatory bowel disease. Gastroenterology 2011;141:1612-1620.
218. Kotlyar DS, Lewis JD, Beaugerie L, et al. Risk of lymphoma in patients with inflammatory bowel disease treated with azathioprine and 6-mercaptopurine: a meta-analysis. Clin Gastroenterol Hepatol 2015;13:847-858.

219. Kotlyar DS, Osterman MT, Diamond RH, et al. A systematic review of factors that contribute to hepatosplenic T-cell lymphoma in patients with inflammatory bowel disease. Clin Gastroenterol Hepatol 2011;9:36-41.

220. Ariyaratnam J, Subramanian V. Association between thiopurine use and nonmelanoma skin cancers in patients with inflammatory bowel disease: a meta-analysis. Am J Gastroenterol 2014;109:163-169.

221. Long MD, Martin CF, Pipkin CA, Herfarth HH, Sandler RS, Kappelman MD. Risk of melanoma and nonmelanoma skin cancer among patients with inflammatory bowel disease. Gastroenterology 2012;143:390-399.

222. Peyrin-Biroulet L, Khosrotehrani K, Carrat F, et al. Increased risk for nonmelanoma skin cancers in patients who receive thiopurines for inflammatory bowel disease. Gastroenterology 2011;141:1621-1628.

223. Rieder F, Latella G, Magro F, et al. European Crohn's and colitis organisation topical review on prediction, diagnosis and management of fibrostenosing Crohn's disease. J Crohns Colitis 2016;10:873-885.

224. Spinelli A, Correale C, Szabo H, Montorsi M. Intestinal fibrosis in Crohn's disease: medical treatment or surgery? Curr Drug Targets 2010;11:242-248.

225. Van Assche G, Geboes K, Rutgeerts P. Medical therapy for Crohn's disease strictures. Inflamm Bowel Dis 2004;10:55-60.

226. Bettenworth D, Gustavsson A, Atreja A, et al. A pooled analysis of efficacy, safety, and long-term outcome of endoscopic balloon dilation therapy for patients with stricturing Crohn's disease. Inflamm Bowel Dis 2017;23:133-142.

227. Bemelman WA, Allez M. The surgical intervention: earlier or never? Best Pract Res Clin Gastroenterol 2014;28:497-503.

228. Latella G, Cocco A, Angelucci E, et al. Clinical course of Crohn's disease first diagnosed at surgery for acute abdomen. Dig Liver Dis 2009;41:269-276.

229. de Buck van Overstraeten A, Wolthuis A, D'Hoore A. Surgery for Crohn's disease in the era of biologicals: a reduced need or delayed verdict? World J Gastroenterol 2012;18:3828-3832.

230. Bobanga ID, Bai S, Swanson MA, et al. Factors influencing disease recurrence after ileocolic resection in adult and pediatric onset Crohn's disease. Am J Surg 2014;208:591-596.

231. Yamazaki Y, Ribeiro MB, Sachar DB, Aufses AH Jr, Greenstein AJ. Malignant colorectal strictures in Crohn's disease. Am J Gastroenterol 1991;86:882-885. 
232. Lovasz BD, Lakatos L, Golovics PA, et al. Risk of colorectal cancer in Crohn's disease patients with colonic involvement and stenosing disease in a population-based cohort from Hungary.

J Gastrointestin Liver Dis 2013;22:265-268.
233. Chang CW, Wong JM, Tung CC, Shih IL, Wang HY, Wei SC. Intestinal stricture in Crohn's disease. Intest Res 2015;13:19-26. 